ISSN: 0514-7336

DOI: http://dx.doi.org/10.14201/zephyrus2019846388

\title{
PIEZAS DISCOIDALES RECORTADAS EN CERÁMICA: PERSPECTIVA DESDE UN DEPÓSITO ÍBERO DE ILIBERRI (GRANADA)
}

\section{Potsherd disks: appraisal from the ensemble of an Iberian deposit in Iliberri (Granada)}

\author{
Daniel Moreno Rodríguez* y Andrés María Adroher Auroux** \\ * Avda. Mesón del Arroyo, edif. 18, 2. ${ }^{\circ}$ B. 18300 Loja (Granada). Correo-e: danielmoreno.1394@gmail.com. ID \\ ORCID: https:/lorcid.org/0000-0001-5117-0841 \\ ** Dpto. de Prehistoria y Arqueología. Facultad de Filosofía y Letras. Univ. de Granada. Campus Universitario de \\ Cartuja. 18071 Granada. Correo-e: addroher@ugr.es. ID ORCID: https://orcid.org/0000-0002-0795-0557
}

Recepción: 17/06/2019; Revisión: 20/07/2019; Aceptación: 22/09/2019

Resumen: En este trabajo presentamos unas piezas consideradas menores por sus características formales: fragmentos de cerámica vascular recortados de los que se analizan sus diversas funcionalidades. Para ello nos centramos en un hallazgo concreto, el depósito votivo íbero de Iliberri datado en el s. IV a. C. Hemos estudiado estas piezas valorándolas dentro de su contexto arqueológico para tratar de entender la relación entre la funcionalidad de estos objetos, su analogía y los paralelismos con otros estudios contextuales. Para ello, hemos seleccionado los ejemplos más significativos intentando determinar, por un lado, las diferentes variantes de formas sobre las que se han recortado las piezas discoidales y, por otro, intentando clarificar el uso de las mismas.

El análisis y el contraste del contexto que presentamos, correspondiente al hallazgo granadino de la c/ Zacatín, y de otros contextos arqueológicos similares que hemos logrado identificar en la bibliografía arqueológica nos permiten afirmar que para llegar a una correcta interpretación de estas piezas es necesario valorarlas dentro de análisis contextuales, iconográficos y tecnológicos.

Palabras clave: Bastetania; Protohistoria; contexto ritual; ofrendas; depósito del Zacatín; analogía.

АвSTRACT: In this paper we present some pieces considered insignificant by their formal features: fragments of vascular ceramics cut from which their various functionalities are analysed. For this reason we have focused on a specific find, the Iberian votive deposit of Iliberri dated in the $\mathrm{I}^{\mathrm{th}}$ century BC. We have studied these pieces, evaluating them within their archaeological context in order to try to understand the relationship between the functionality of these objects, their analogy and the parallels with other contextual studies. With that in mind, we have selected the most significant cases, trying to determine, on the one hand, the different variants of shapes on which the discoidal pieces have been cut and, on the other, trying to clarify their use.

The analysis and contrast of the context that we present, corresponding to the Granada discovery in the Zacatín Street, and other similar archaeological contexts that we have been able to identify in the archaeological bibliography, allow us to affirm that in order to arrive at a correct interpretation of these pieces it is necessary to evaluate them within contextual, iconographic and technological analyses.

Key words: Bastetania; Protohistory; ritual context; offerings; Zacatín deposit; analogy. 


\section{Introducción}

En 1999 se llevó a cabo una intervención arqueológica de urgencia en la c/ Zacatín de Granada, en la cual se localizó un importante depósito de materiales datado en la primera mitad del s. IV a. C. (Fig. 1). De la excavación apenas contamos con un pequeño informe técnico. La mayor parte de las publicaciones que han visto la luz después de la intervención se han centrado en el estudio del contenido material del depósito y no del contexto en sí (Rambla y Salado, 2002). Resumiendo las características de este último, cabe señalar que el hallazgo tuvo lugar fuera del barrio del Albaicín, que es donde se considera que estaría el oppidum de Iliberri. Durante la intervención se localizaron varios niveles arqueológicos (Figs. 2-4), siendo la fase más antigua la que se relaciona con el material que ahora presentamos y que se data en el s. IV a. C.
Se trataba de una fosa cuadrangular de no más de $25 \mathrm{~cm}$ de profundidad, sin relación estructural ni estratigráfica con ningún otro elemento. La fosa fue excavada sobre los depósitos fluviales del río $\mathrm{Da}$ rro, por lo que es más que probable que una parte importante de su forma y de los materiales que se incluyeron haya sido alterada por la acción del agua y su movimiento de arrastre, presentando, por ello, el conjunto procesos tanto erosivos como sedimentarios. La siguiente fase documentada en la excavación se corresponde con una construcción de época nazarí, un espacio destinado a tiendas y almacenes, incluyendo tinajeros in situ que no se amortizaría hasta el s. Xvi.

Este depósito venimos interpretándolo como una ofrenda de la comunidad del oppidum de Iliberri -antigua Granada-, tanto por su ubicación -en la orilla del río-, como por su posición -extramuros al poblado-. Por la ausencia de estructuras en el

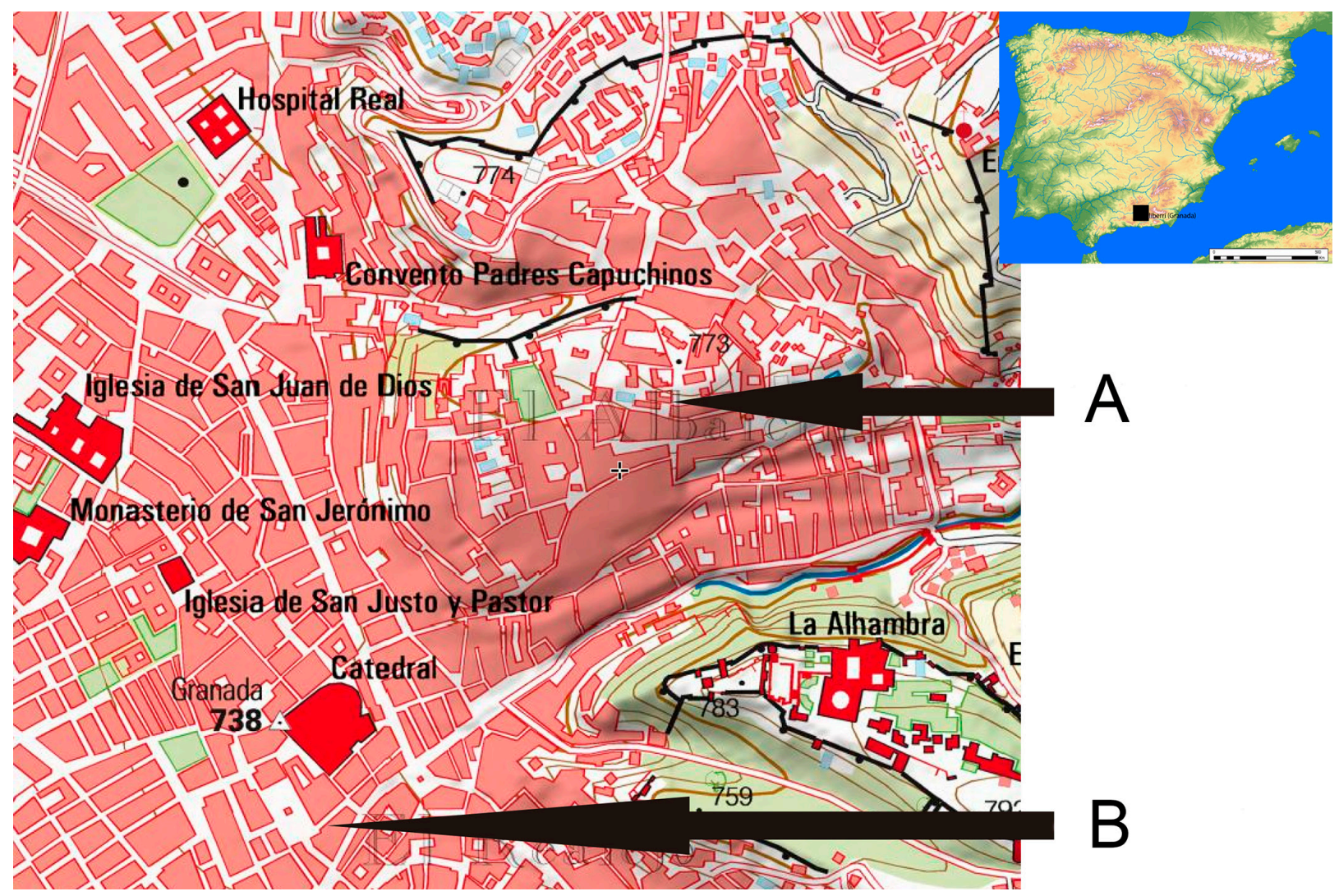

FIG. 1. A) Ubicación de Iliberri, posición del oppidum en el barrio del Albaicin (Granada). B) localización del lugar de hallazgo del depósito votivo (elaboración propia a partir de IBERPIX). 


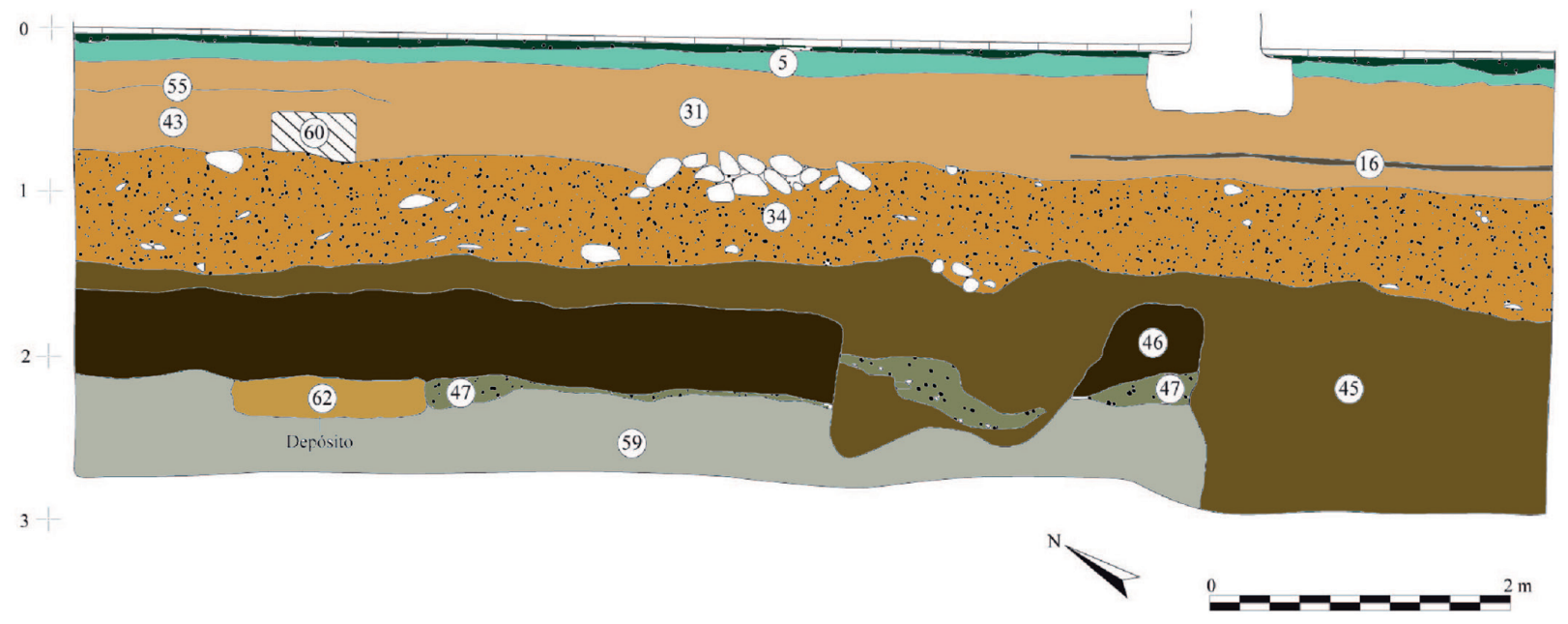

Fig. 2. Sección del perfil oriental del corte realizado en la calle Zacatín (Rambla y Salado, 2022: fig. 2).

entorno descartamos la posibilidad de que se tratase de un silicernium dentro de un contexto funerario tal como se pensó inicialmente (Rambla y Salado, 2002: 184). Por otra parte, su propia naturaleza, una fosa rellena con más de 5.000 fragmentos de cerámica y otros objetos, permite suponer una obliteración del depósito mediante fuego ritual. La inexistencia de estructuras próximas, así como la temporalidad del mismo, nos permite considerarlo como un acto puntual ${ }^{1}$.

El estudio de materiales nos ha permitido proponer que se trata de un depósito, sin elementos funerarios en relación, posiblemente relacionado con un festín que tuvo lugar, de forma aislada y puntual, en torno al 370-360 a. C. El efecto del agua del río provocaría la pérdida de parte del material original llevado más abajo por la corriente, al mismo tiempo que se incorporarían otros materiales, algunos más antiguos y otros más modernos, al encontrarse el oppidum ibérico - posterior ciudad romana- apenas medio kilómetro río arriba. Sobre la naturaleza del depósito y sus problemas deposicionales y posdeposicionales remitimos a una publicación anterior (Adroher et al., 2015: 42-44).

A la hora de analizar cuantitativamente los materiales que componen este hallazgo hay que tener en cuenta que nos enfrentamos al desconocimiento anteriores.

Cf. Sol et al., 2018, con referencias bibliográficas

(C) Universidad de Salamanca

Chiversidad de Salamanca de la extensión total del contexto arqueológico en que fueron hallados, ya que al tratarse de una intervención de urgencia no se exploró el depósito, al penetrar el mismo en uno de los perfiles del sondeo. Es necesario tener en cuenta esta circunstancia, ya que supone un sesgo en la naturaleza de la documentación con la que contamos, y entender que el depósito es solo la muestra de un conjunto cuya extensión y representación numérica desconocemos.

El conjunto de los materiales del depósito presenta una composición extraordinariamente variada (Fig. 5) pues encontramos: cerámicas áticas -barniz negro y figuras rojas-, cerámicas íberas -barniz rojo, comunes, cocina, pintadas y ánforas-, cerámicas de otras procedencias - púnicas centromediterráneas y púnico-hispánicas-, otros elementos cerámicos -fusayolas-, metales -hierros y bronces-, ungüentarios de pasta vítrea, cáscaras de huevo de avestruz, una placa orientalizante en hueso y escasísimos restos de macrofauna.

Entre la cerámica vascular resalta la gran cantidad y variedad de producciones griegas, de las que destacamos, por un lado, las de barniz negro con copas Tipo c, kylikes con y sin resalte, bolsales, copas Cástulo, platos de pescado, dos gutti, algunos skyphoi y una gran cantidad de páteras tanto de borde entrante -incourving rim- como con borde engrosado al exterior-outturned rim-. Entre las áticas de figuras rojas cabe resaltar los kylikes del tipo clase 


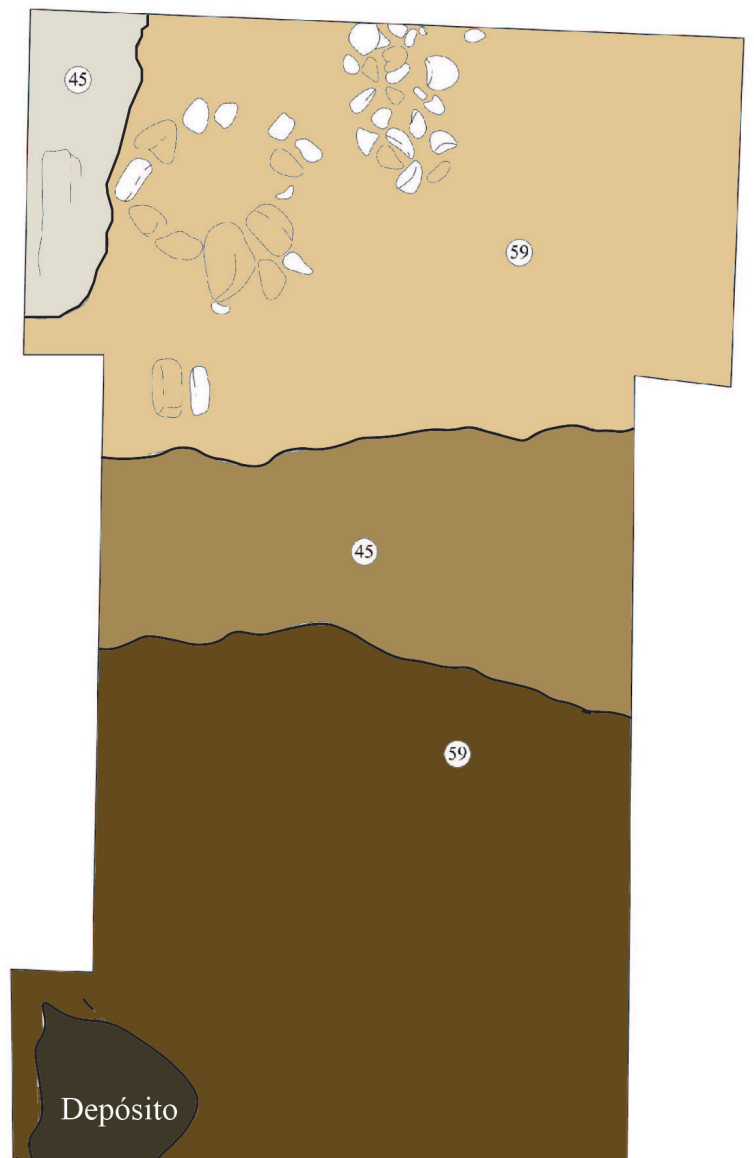

FIG. 3. Planta de la excavación en la calle Zacatín (Rambla y Salado, 2002: fig. 3). delicada - delicate class-, donde predominan las decoraciones características del Pintor de Viena 116, y que son el tipo mejor representado en el conjunto total del depósito. Son muy escasas las cerámicas indígenas, básicamente cuencos, urnas y ánforas. El mayor porcentaje se corresponde con unos platos de borde vuelto y resalte interno (Fig. 5, n. ${ }^{\circ}$ 17), que parecen emular piezas metálicas, y de los que no se conocen paralelos en ningún lugar, ni siquiera en contextos de Iliberri; la peculiaridad del perfil, así como la gran cantidad de ellos -más de 20 ejemplares reconocibles-, nos permiten considerar la hipótesis de que se trate de una producción específicamente fabricada para este ritual (Sánchez Moreno et al., 2015).

Desde hace algo más de 15 años nos hicimos cargo del estudio de los materiales de este depósito, conservados en el Museo Arqueológico y Etnológico de Granada. Desde entonces hemos llevado a cabo una política de estudio y publicación de cada una de las agrupaciones de tipos de materiales que presenta -cerámicas indígenas, cerámicas griegas, huevos de avestruz, placa de hueso, etc.-, con el objetivo de poner en conocimiento de la comunidad científica la composición completa de esta ofrenda. En esta línea proponemos este trabajo: un estudio

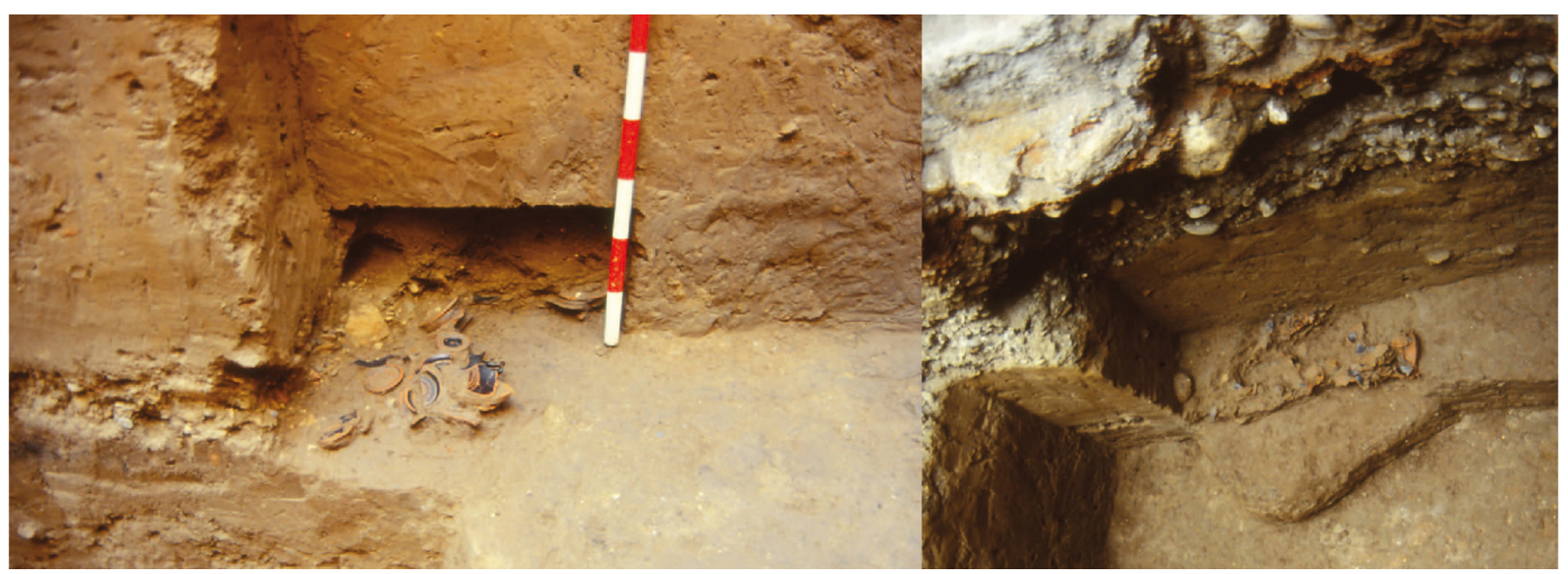

FIG. 4. Dos imágenes del hallazgo (archivo: TIA). 

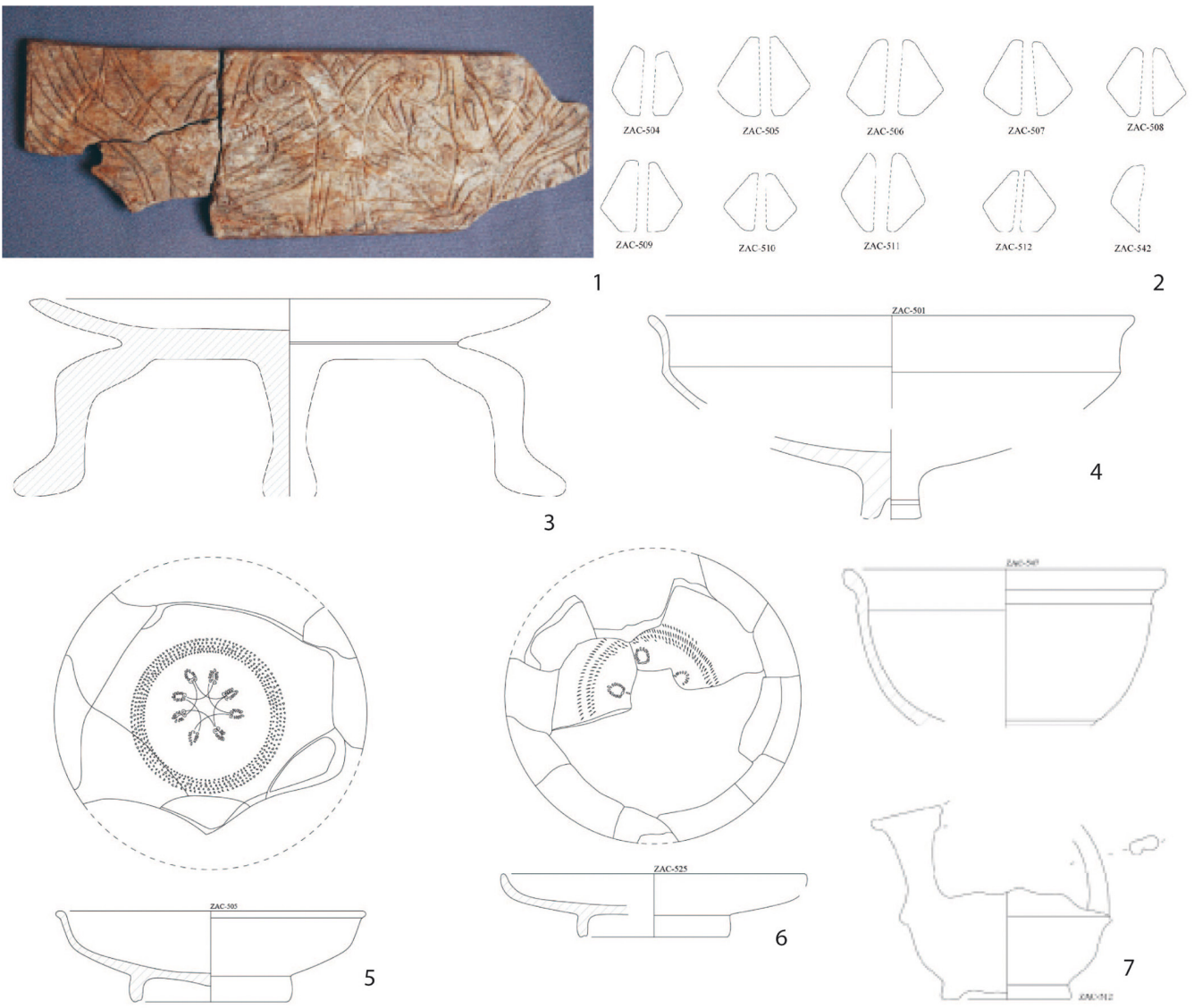

3
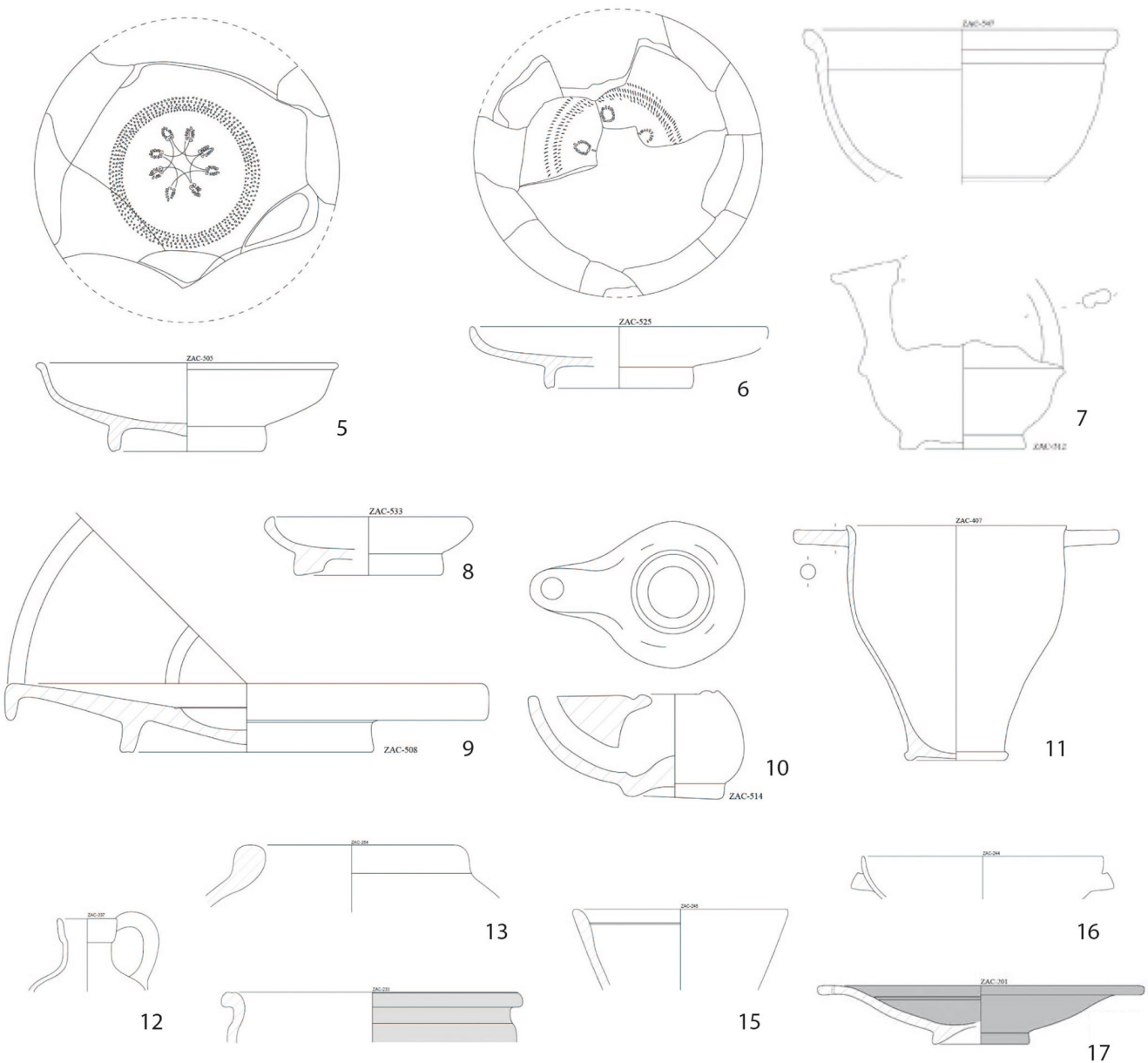

14

FIG. 5. Selección de material procedente del depósito de la cl Zacatín: 1) placa de hueso orientalizante; 2) conjunto de 10 fusayolas; 3) soporte trípode en bronce; 4-11) cerámica ática de barniz negro; 12) jarrita de cerámica púnica centromediterránea tipo Lancel 521; 13) ánfora ibérica; 14) urna pintada monócroma ibérica; 15) cuenco profundo de cerámica común ibérica; 16) copa de imitación ática en común ibérica; 17) plato de engobe rojo. 
específico sobre piezas discoidales, elementos que han sido recortados, para diversas finalidades, sobre fragmentos de vasos de cerámica. El conjunto de las piezas discoidales se caracteriza por dos aspectos muy concretos: en primer lugar, cuantitativamente no es muy numeroso, lo cual no da mucho juego a la hora de organizar un análisis ni de construir una interpretación fiable. Por otro lado, presenta rasgos muy particulares, pues, a pesar de la poca cantidad de piezas, en estas hemos podido detectar al menos tres fenómenos bien distintos que responden a criterios diferentes a la hora de su realización. A pesar de todo, la información que nos ofrecen es muy valiosa por ser un conjunto perfectamente contextualizado; en el caso de otros yacimientos en los que se encuentran gran cantidad de piezas recortadas, estas no parecen presentar una variabilidad de casos tan amplia, al menos eso parece al revisar los datos de las que han sido publicadas.

En este sentido cabe resaltar la falta de estudios publicados sobre este tema que merma la posibilidad de establecer paralelos y analogías. Esto nos hace avanzar con pequeños pasos para poder esclarecer, sobre todo, las cuestiones relacionadas con la funcionalidad de las piezas discoidales.

\section{Estado de la cuestión}

Para iniciar esta revisión comenzamos por analizar brevemente la situación que encontramos en relación a las piezas recortadas en el conjunto general de la Península Ibérica. Hemos partido de algunas referencias puntuales a fenómenos similares observados en otros países, esperando encontrar así suficientes paralelos contextualizados que puedan arrojar alguna luz sobre las funcionalidades de estas piezas en general, y sobre las que encontramos en el contexto del depósito votivo del Zacatín en particular.

Como ya sabemos, el ser humano ha optimizado los recursos naturales de que disponía, llegando con frecuencia al reaprovechamiento incluso de sus propias manufacturas. En muchas ocasiones estas reutilizaciones convierten el objeto inicial en otro con un fin diferente al cambiar la función primaria que desempeñaba; unas veces las modificaciones afectan al campo morfológico y otras al técnico. En este proceso la naturaleza del producto determina las posibilidades de la recuperación para funciones similares o distintas a las originalmente destinadas. En el caso de la cerámica, la amortización del objeto se produce, generalmente, como consecuencia de una fracturación lo suficientemente importante como para deshabilitar la posibilidad de recuperarlo para su función original. En cambio, para el caso de algunos metales tecnológicamente recuperables -en la Antigüedad casi todos, salvo el hierro-, bastaba con reciclar la materia prima refundiéndola. Sin embargo, para materiales como la cerámica o la piedra, no existe la posibilidad de malearla hasta el punto de crear un objeto nuevo, del todo diferente al original, ya que no se puede volver a moldear; cabe solamente la posibilidad de adaptar lo existente. Surge así una amplia variabilidad de respuestas ante la amortización de un objeto cerámico como puede ser la reparación, la reutilización o el reciclado (Peche-Quilichini et al., 2017), cada una de las cuales responde a una serie de criterios tecnológicos, sociales y culturales extraordinariamente complejos como para revisar sus relaciones en este texto (Fig. 6).

Los vasos cerámicos pueden ser reutilizados en una gran diversidad de contextos: uno de los ejemplos más evidentes lo tenemos en el caso de las ánforas, que, pese a ser una manufactura con un proceso de fabricación y con una funcionalidad muy específicas, las podemos encontrar reutilizadas en el campo constructivo para hacer tuberías -Dressel 1 en el s de la Galia-, como aliviadero de cubiertas -en el templo de Minerva Médica-, soportes para hoyos de postes, asiento de muros a modo de ripios -en yacimientos como la antigua Lattara-, trituradas como parte de la argamasa en obra hidráulica -en la fabricación de opus signinum-, etc. También pueden encontrarse en otros ámbitos como urnas de enterramiento -a modo de enchytrismos- o como sistemas de almacenaje -las íberas en el Cerro de la Cruz de Almedinilla en Córdoba-, manos de mortero o pesas de telar-casos de las asas etruscas en la Galia o de las púnico-ebusitanas en las Baleares-, 

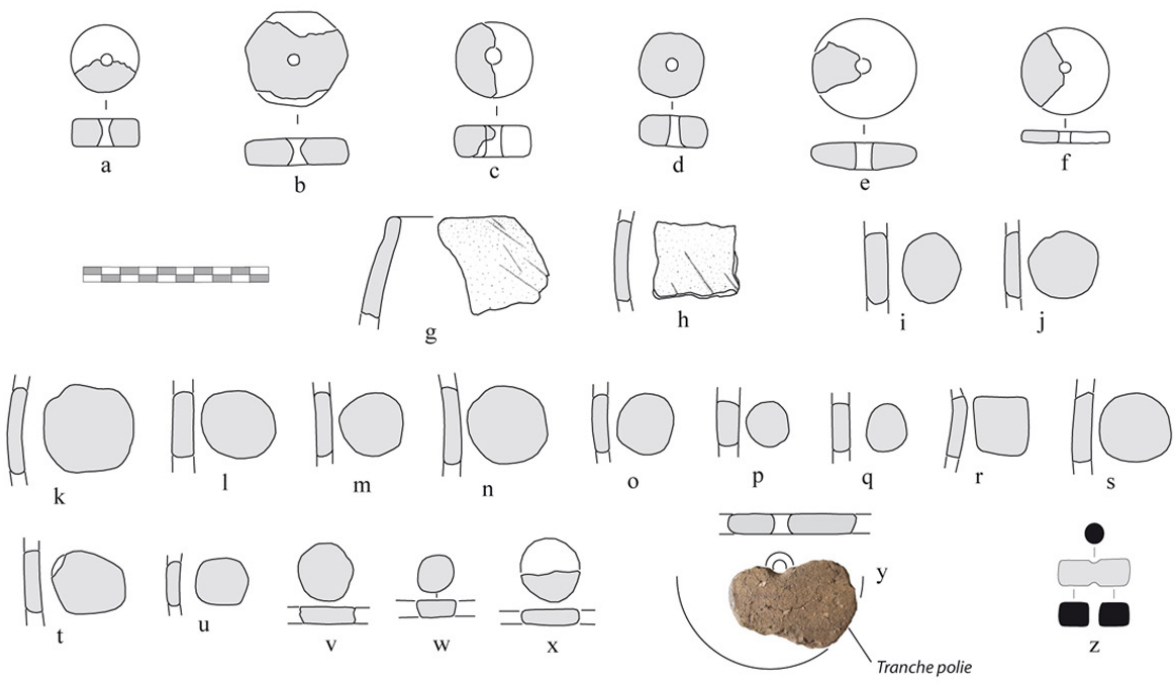

Fig. 6. Fragmentos cerámicos recortados con distintos formatos (Peche-Qulichini et al., 2017: fig. 7).

elementos votivos -en el Silo 101 de Mas Castellar de Pontós-, filtro de agua -las T-5 centromediterráneas en Emporion-, entre un largo etcétera que no pretendemos agotar aquí.

En definitiva, una vez que los objetos se rompen, o simplemente quedan obsoletos, se arreglan -generalmente reparados mediante lañado- para que sigan funcionando o bien sufren alteraciones para darles otros usos -fracturándolos por zonas concretas, ańadiendo o eliminando parcialmente algunas de sus partes, etc.-. Este fenómeno de recuperación ha estado presente hasta hace unos 50 años, en que comenzó a imponerse un modelo productivo favorecedor del consumo, más que criticable y poco responsable con los recursos naturales, que provoca que los grupos sociales con más capacidad económica -incluso los de menor capacidad- se permitan el lujo de adquirir nuevos productos antes que arreglar o reutilizar los que tienen en uso, desechándolos por cualquier motivo, aunque sea simplemente el gusto estético².

Desde hace poco tiempo se ha empezado a prestar atención a un fenómeno detectado con frecuencia

2 Solo apuntamos esta evidencia sin querer profundizar sobre las conclusiones de la Garbage Archaeology en relación al reciclado de material y la producción de basura dependiendo de la capacidad económica de los distintos grupos sociales en el mundo occidental contemporáneo. en contextos muy específicos, lo que permite manejar un registro más amplio. Como ya venimos indicando, por estos motivos no hay mucha bibliografía disponible al respecto.

Sabemos que este tipo de materiales los podemos encontrar desde el Neolítico hasta al menos la Edad Moderna -como hemos podido constatar en algunas excavaciones de urgencia dentro de contextos urbanos en el caso de Granada-, si no ya la Contemporánea. A esta enorme amplitud temporal en el uso de estas piezas, debemos añadirle la extraordinaria amplitud espacial, pues, por lo que sabemos, se encuentran claramente constatadas en las culturas ribereñas del Mediterráneo, incluido Egipto (Nelson, 2001). Aunque parece tratarse de un fenómeno mucho más generalizado, pues también se encuentran en América del Norte con una cronología que abarca desde la época precolonial hasta la actualidad (Potter y Brown, 2011) y en América del Sur (Silverman, 1993: 260). Por tanto, es más que posible que nos encontremos ante un fenómeno asociado a gran parte de culturas del pasado.

Las piezas con forma discoidal, más o menos recortadas, son conocidas desde el Neolítico, donde suelen aparecer fabricadas en dos materias distintas: piedra y cerámica. La preparación de los bordes presenta solo dos formatos, fragmentación por presión o por percusión. Parece que la más frecuente es la 
primera, que suele producir perfiles más o menos concoideos dependiendo de la granulometría de la materia prima -en una cerámica a torno tiende a ser más neta que una cerámica de pasta grosera-. Además, pueden estar pulimentados y frecuentemente aparecen con una perforación en el centro, lo que ha llevado a algunos investigadores a considerarlas piezas de telar (Herrera y Gómez, 2004: 279-280). No obstante, hay que señalar que eventualmente pueden encontrarse ambas técnicas utilizadas sobre la misma pieza.

Respecto a la Antigüedad apenas tenemos algunas referencias concretas de sus funciones y sus nombres. Cuando se valoran como fichas de juego reciben el nombre de pessoi, relacionadas con juegos como el ludus latrunculorum; en otras ocasiones, cuando aparecen con inscripciones incisas con el nombre de algún personaje, se consideran fichas de voto, conocidas con el nombre también griego de ostraka, siendo quizás la colección con la inscripción Themisthokles neokleos, del Museo de Ágora de Atenas, uno de los conjuntos más curiosos (Fig. 7). También se han relacionado con la higiene personal (Charlier et al., 2012) (Fig. 8). Otras opciones interpretativas pueden corresponder a fusayolas para el huso, a piezas usadas en un sistema de conteo, pesas de telar, tapaderas de olla (Rizkana y Seeher, 1989: 12) y una amplitud de propuestas que complican la posibilidad de establecer una relación

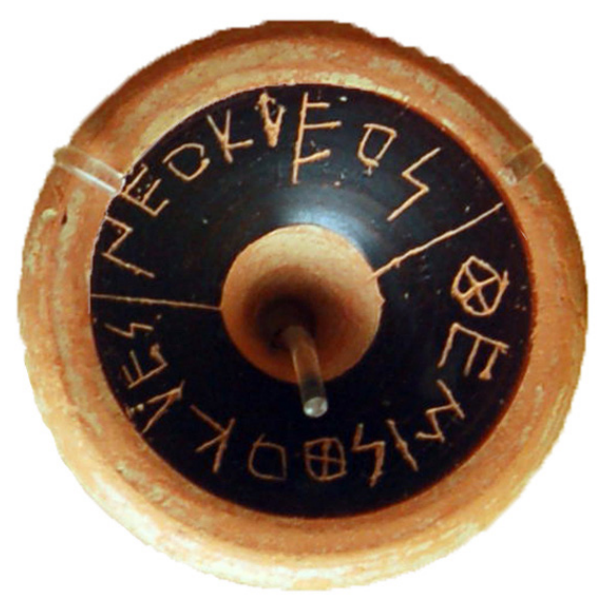

FIG. 7. Fondo de copa de pie alto ática con grafito con el nombre de Themisthokles.
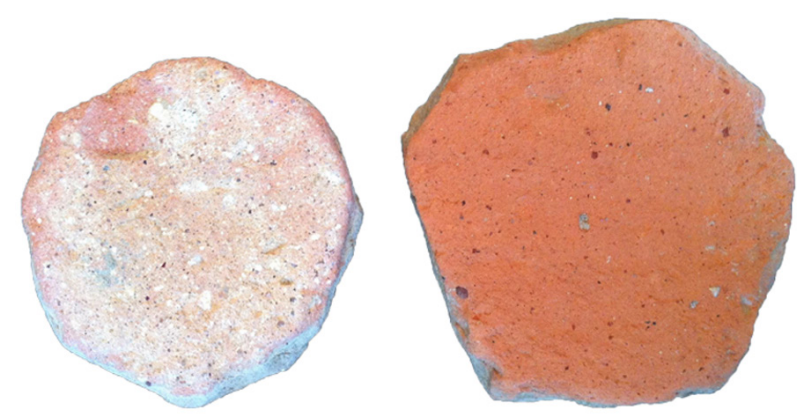

FIG. 8. Ejemplos de pessoi en terracota procedentes de letrinas del siglo II d. C. (Charlier et al., 2012: fig. 1).

directa entre forma y uso. En consecuencia, debe apostarse por los estudios de contextos específicos -espaciales y temporales- para poder establecer propuestas sólidas, al menos aplicables a esos parámetros concretos. A pesar de ello, su estudio sigue resultando altamente complejo.

Tal como venimos refiriendo, estas piezas, de complicada interpretación y esporádica presencia, pocas veces han sido objeto de estudios contextuales; excepcionalmente podemos citar el caso de Can Miano en Sant Feliu de Llobregat, donde se localizaron más de 900 recortes cerámicos ${ }^{3}$, o el del Pozo I, 13:4 de la Stoa Media de Atenas (Fig. 9), cuyo relleno data en torno al 700 a. C., pero cuyo número exacto no se ha publicado (Papadopoulos, 2002).

Quizás una de las obras más importantes, la única especializada en esta línea y escrita en español, sea el estudio realizado por Z. Castro (1978) sobre piezas recuperadas en tres yacimientos íberos gerundenses: Mas Castellar de Pontós, Ullastret y Porqueres. En este trabajo Castro clasificó las piezas en función de las características físicas que presentaban, especialmente las dimensiones, y propuso una serie de funciones basadas más en la intuición que en los estudios contextuales, o en los análisis de las huellas de fabricación o de uso, o en experiencias etnográficas. Solo analiza un tipo de piezas recortadas, las que tradicionalmente se han conocido como fichas de juego -pessoi en gran parte de la bibliografía-;

3 Solías, J. M.: El poblament del curs inferior del Llobregat en época ibèrica i romana, p. 1613. Tesis doctoral inédita presentada en 1990 en la Univ. de Barcelona. 
es decir, se limita a aquellas que han sido recortadas sobre fragmentos de las paredes de los vasos, dejando de lado otras opciones, como los recortes sobre los fondos que, a pesar de mencionarlos, no se incluyen en el análisis, posiblemente porque la cantidad de ejemplares de este tipo es bastante menos representativa.

En este caso hay que lamentar la escasa muestra analizada determinada por la adscripción espacial -provincia de Gerona- y cronológica -época íbera-, lo que limita enormemente las posibilidades de hacer valoraciones generales y aún más de extrapolar los resultados a otros lugares, sin que ello reste importancia a la publicación.

También podemos resaltar algunos estudios de conjuntos con una buena representación de piezas discoidales, como es el caso de Olèrdola (Molist, 2009), donde se detectó una acumulación de 139 piezas realizadas en varias materias y con diversas cronologías que iban desde el Bronce Final a la

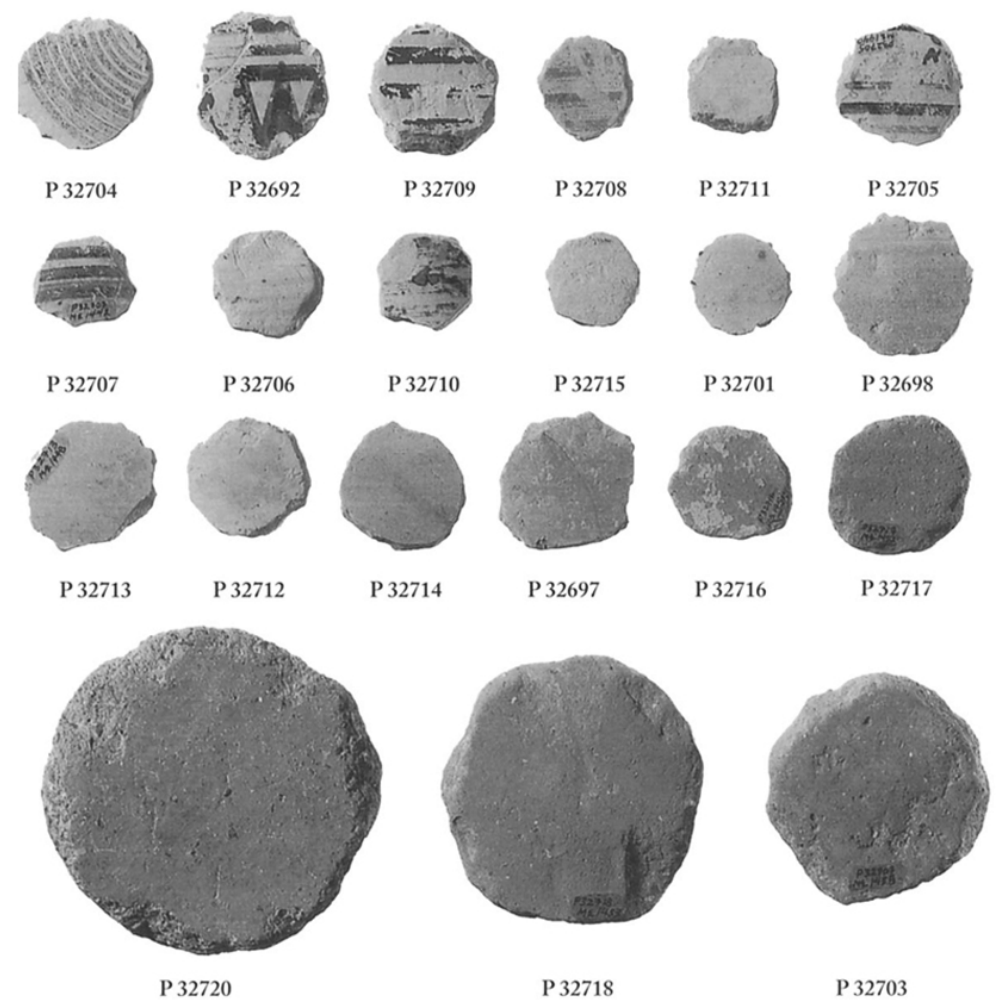

FIg. 9. Piezas discoidales procedentes del Pozo I, 13:4 del ágora de Atenas (Papadopoulos, 2002: fig. 5).
Edad Media. Tomaron como materia prima elementos muy diversos: cerámica vascular, cerámica de construcción, vidrio y piedra. La mayor parte de las piezas son de cronología íbera -71,94\%-, aunque solamente un 30,22\% aparecen en contexto, ya que el resto fueron localizadas en fases posteriores. Encontramos piezas de grandes dimensiones, una en concreto con un diámetro de $10-13 \mathrm{~cm}$ que se puede interpretar como una tapadera. Algunas de ellas presentan el retallado que ha sido pulido posteriormente, que es muy evidente en el caso de una realizada sobre cerámica de barniz negro; otra, de muy pequeñas dimensiones $-2 \mathrm{~cm}-$, presenta entalles dentados en el borde y está realizada sobre un fragmento de sigillata itálica. Ambas, por el cuidado en el proceso de recorte y su terminación, así como por el hecho de haber sido elaboradas sobre fragmentos barnizados, fueron interpretadas como fichas de juego. Otro de los ejemplares encontrados apareció con una perforación en el centro, y estaba realizado sobre un fragmento de dolium, lo que invita a la investigadora a considerar que se trata de un pondus de telar. Finalmente, resalta una sobre la cual se ha practicado una incisión cruciforme, señal que según algunos autores tendría un valor nominal de medida (Panosa, 1998: 462). En cuanto a la parte del vaso elegida para fabricar las piezas, la mayor parte se realiza sobre paredes, pero dos de ellas están elaboradas sobre el fondo del vaso - una sobre barniz negro de Rosas con estampilla central y otra sobre un fondo de cerámica común íbera-; son precisamente las que la autora interpreta como tapaderas, considerando que el pie puede servir para tirar de la pieza, a modo de asidero. Pesamos que esta interpretación puede estar un poco forzada. Para finalizar queda indicar que el $83,45 \%$ de los ejemplares de este contexto provienen de las fases íbera y romana.

Otro conjunto que ha sido publicado es el de Puig de la Nau (Oliver y 
Gusi, 1995: 167-168), aunque no proceden de un mismo contexto, pero su análisis fue objeto de uno de los textos más amplios y reflexivos sobre este tipo de piezas durante mucho tiempo, solo superado por el de Z. Castro.

En una reciente excavación realizada en una estructura de producción rural romana en el término municipal de Rute, en la provincia de Córdoba, aparecieron 15 piezas discoidales. Dos de ellas fueron recortadas sobre paredes de cerámica común; otras dos sobre fragmentos de material latericio; una sobre la pared de un dolium; una perforada sobre cerámica de cocina; ocho sobre fondos de cerámica común, uno de ellos perforado. Sin embargo, no apareció ninguna pieza discoidal que estuviera recortada sobre cerámica de alta calidad, como sigillata. Tratándose de un centro de producción y transformación agrícola, parece lógico que no aparezcan piezas destinadas al juego y que todas las encontradas tengan algo que ver con un proceso de control de cantidades (Adroher et al., 2018); aun así, podemos comprobar la amplitud fenomenológica que pueden presentar incluso procediendo de contextos funcionales y cronológicos relativamente homogéneos.

En los materiales provenientes de los trabajos de prospección superficial del yacimiento ibérico almeriense de Montagón, en Abla, se ha detectado una inusitada cantidad de piezas discoidales realizadas sobre paredes de cerámica común ibérica (Adroher, 2016). Este asentamiento, por su posición dentro de las rutas de comunicación en el entorno de la antigua Acci, debió jugar un papel esencial en el territorio, por lo que posiblemente podamos considerarlo un poblado con un fuerte componente económico. Esto quizás se ha reflejado en la presencia inusitada de piezas discoidales, por lo que quedaría claro que una de sus funciones estaría relacionada, como se comentó anteriormente, con sistemas de conteo de productos.

Lamentablemente, los estudios comparativos resultan difíciles de realizar, ya que, como venimos diciendo, solo eventualmente se mencionan estas piezas en las publicaciones sobre materiales $\mathrm{y}$, cuando se hace, normalmente es de forma muy breve
(Morena, 1991: 102). Su escasa representatividad provoca que apenas se clasifiquen y que no contemos con los datos suficientes para estudiarlas con mayor precisión. En la mayoría de las ocasiones, las referencias existentes se limitan casi exclusivamente a la documentación gráfica del resultado de alguna intervención. Las piezas apenas se describen en un párrafo pasando desapercibidas, pese al interés que pueda suscitar el conjunto en el que se han encontrado (Olmos, 1988-89; Olmos y Tortosa, 2009).

\section{El conjunto del Zacatín}

En este conjunto encontramos una amplia variedad formal, y en consecuencia posiblemente funcional, de los materiales que venimos considerando como piezas discoidales recortadas. Debido a la naturaleza del soporte utilizado, no nos cabe duda alguna de que la mayoría procede sistémicamente del depósito y que, por tanto, debieron jugar algún papel en el ritual, durante el momento en que se realizó, entrando dentro del conjunto material que se amortizó posteriormente. Pasamos a analizar caso por caso.

\subsection{Piezas recortadas sobre paredes}

En estos casos la pieza discoidal se obtuvo del recorte de la pared de la cerámica vascular, por lo que no suele corresponder a un fragmento diagnóstico del vaso, sino a un amorfo. Esta es, de todas las opciones que hemos visto, el modelo más frecuente, especialmente en época íbera y romana.

En la mayoría de los casos se han recortado sobre clases cerámicas comunes o finas. Se documentan prácticamente en todos los contextos imaginables: domésticos, productivos, votivos o funerarios. De hecho, es, con mucho, el formato más documentado en todas las publicaciones y el más referenciado, incluso en la obra ya referida de Castro (1978).

Se encuentran en ámbitos funerarios como El Cigarralejo; concretamente, están presentes en las Tumbas 62, 173, 177, 239, 291 y 343, asociadas en 
algunos casos a individuos infantiles y adolescentes, e incluso en otras en las que se han identificado restos óseos de animales (Cuadrado, 1987). También se hallan en espacios sagrados como es el caso de las 18 piezas en el depósito votivo del Amarejo (Broncano, 1989). En otras ocasiones parece tratarse de piezas a medio elaborar, como las perforadas de Armea, en Allariz (Orense) (Rodríguez Novoa, 2014). En el poblado íbero de Mas Castellar de Pontós se recuperaron muchas piezas en contextos diversos, algunos de ellos asociados a hornos, lo que permitiría establecer una relación funcional, como contadores de unidades de pan en un espacio productivo comunitario. Otro interesante ejemplo perteneciente a este yacimiento catalán es la famosa pieza conocida con el nombre de ostrakon, aparecida en el Silo 25, que contiene una amplia inscripción incisa en su superficie que se ha interpretado como un listado de nombres (Panosa, 2002). Es curioso que algunos de los casos, como el anteriormente mencionado, se documentan con cierta frecuencia en el interior de algunos silos. Especialmente interesante es el caso del Silo 101, en cuyo relleno, formando parte de un depósito votivo datado entre finales del s. III y principios del II a. C., aparecieron 22 discos que se han asociado a una posible ofrenda femenina (Adroher et al., 1993: 53-54). Finalmente, en este mismo poblado, encontramos un caso de piezas discoidales en contexto funerario, caso del Silo sJ38 (Agustí et al., 2008).

Hay casos de piezas discoidales con grafitti (De Hoz, 2011: 232), aunque no son muy frecuentes (Panosa, 2001), incluso parecen tener funciones especializadas. Es el caso de los conocidos como calculi, entendidos realmente como fichas de juego y frecuentemente realizadas sobre cerámicas finas -sigillata y barniz negro-, sobre los que se ha publicado un interesante trabajo (Pérez González y Arribas, 2016: 91-92).

Finalmente, referimos un espectacular hallazgo que podría responder a un sistema ponderal; se trata de las once piezas localizadas conjuntamente

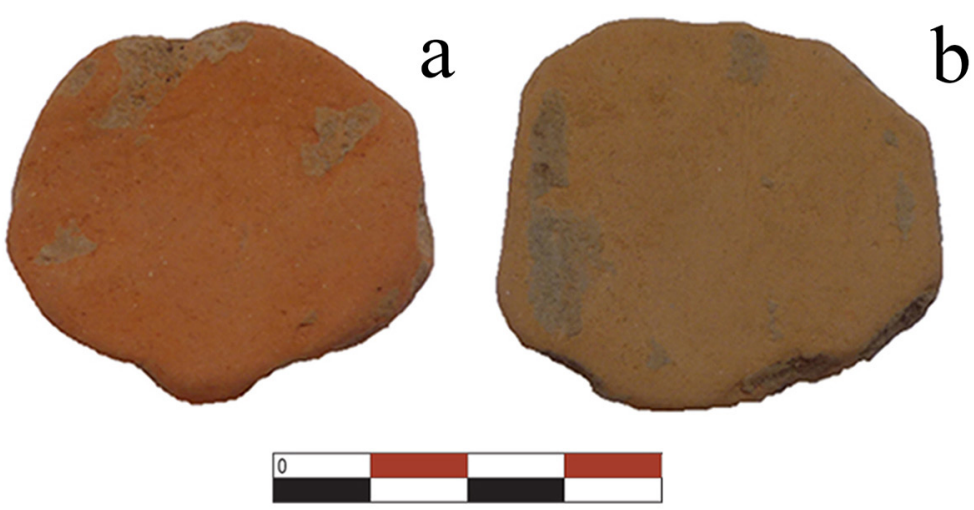

FIG. 10. A) Pieza discoidal recortada sobre amorfo de común ibérica ( . $^{\circ}$ inv. 740); B) Pieza discoidal recortada sobre amorfo de común ibérica (n. ${ }^{\circ}$ inv. 741). en el Departamento 97 de La Bastida de les Alcuses (Fletcher et al., 1969: 270-271), si bien no aparece asociado a ningún otro elemento que pudiera arrojar información; quizás la diferencia en el diámetro de las piezas $-2,9 ; 3,2 ; 3,6 ; 3,8 ; 4,0 ; 4,1 ; 4,7 ; 5,2$; 5,8 y $6,2 \mathrm{~cm}$ - pueda relacionarse con el contravalor que representaría este sistema, basándose más en la dimensión que en el peso.

Volviendo al caso del depósito que aquí presentamos solamente aparecen dos ejemplares de este tipo, por lo que son escasamente representativos en el conjunto. Esto, unido a problemas relacionados con el alto índice de erosión que presentan y a los procesos de alteración que el depósito ha sufrido por su proximidad al lecho del río Darro, induce a plantear que estas piezas no deban considerarse como propias del depósito y que pudieron introducirse como consecuencia de procesos de sedimentación fluvial. No obstante, ya que no contamos con los datos adecuados acerca de su ubicación dentro del contexto, no podemos afirmar con seguridad que son elementos intrusivos. Sobre ellos haremos una reflexión última más adelante. Ahora solo nos queda decir que descartamos que se trate de tapaderas por su reducido diámetro.

Las dos piezas son las siguientes:

- N.o inv. 740 (Fig. 10A): se conserva en un único fragmento que se ha extraído de la pared de un vaso profundo o cerrado de cerámica común íbera y describiendo una suave curva correspondiente al 
perfil original de la pared del vaso. La mitad de la cara interna no se conserva y no se aprecia ningún tipo de tratamiento en el borde. Apenas pueden observarse las huellas de las técnicas de recortado debido a la fuerte erosión que presenta. Medidas: diámetro, 32-40 mm; grosor, 3-5 mm; peso, $14 \mathrm{~g}$.

- N. ${ }^{\circ}$ inv. 741 (Fig. 10B): ficha que se ha conservado en un único fragmento que se ha obtenido a partir del recorte y tratamiento de la pared de algún vaso profundo o cerrado de cerámica común íbera. Tampoco se puede identificar tratamiento alguno de los bordes, por el mismo motivo que en el caso anterior. Medidas: diámetro, 31-42 mm; grosor, $3 \mathrm{~mm}$; peso, $13 \mathrm{~g}$.

Vistas las características técnicas y las dimensiones de ambas piezas, es posible que tanto su función como su cronología difieran muy poco de las del depósito, lo que hace reconsiderar su contexto llevándonos a pensar que pudieran formar parte del conjunto. Sería una coincidencia excesiva que ambas, siendo tan similares, hubiesen llegado hasta allí arrastradas de forma fortuita. Si finalmente se asume que pertenecen al depósito deberíamos considerar que este tipo de piezas, con recortes de fracturas concoideas y no alisadas, podrían formar parte del ámbito sagrado, con un contenido simbólico que, por el momento, está lejos de aclararse.

\subsection{Piezas recortadas sobre el pie}

En esta categoría agrupamos aquellas piezas discoidales que se han recortado cinéndose al contorno del pie o al fondo cerámico. Sus características son muy diversas, encontrando recortes tanto de cerámicas comunes como de importación. A nivel formal estos objetos dependen, en la mayoría de los casos, de las características de los vasos de los que proceden. Suelen ser piezas discoidales planas o con una cierta concavidad, lo que hace pensar que son el resultado de recortar formas abiertas como platos, cuencos o fuentes.

No son siempre fáciles de detectar y, en ocasiones, pasan completamente desapercibidas, ya que podría considerarse que, por una cuestión tecnológica de la propia fabricación de la pieza cerámica, el pie podría haberse desgajado del resto de la pared por tratarse de un elemento normalmente añadido. Sin embargo, esto no suele ser así y el recorte se realiza ex profeso alrededor del anillo de fondo, forzándose para que este se desprenda. Lo único que se suele aplicar contra el fondo son los anillos del pie, siendo fácil que se fracturen por las zonas de unión. Como consecuencia de esto, en muchas publicaciones se detectan estos tipos de piezas recortadas discoidales cuando se incluyen entre la documentación dibujos de la pieza desde una posición cenital, y no solo la sección de la misma. Si no es así resulta imposible detectarlos solo mediante el dibujo de su sección. Un magnífico ejemplo son las piezas localizadas en cuevas santuario íberas levantinas, como un posible Bolsal con fondo decorado en Cerro Hueco o los fondos de caliciformes del Puntal del Horno Ciego II (Machause y Quixal, 2018: 118 y 121). Este es el menor de los grupos cuantitativamente, teniendo en cuenta el análisis de los conjuntos de piezas recortadas que hemos analizado hasta ahora.

Además, dentro de este grupo quizás merezca un tratamiento aparte el caso de los pies con grafitti que aparecen especialmente sobre la base de la peana de copas de pie alto de barniz negro ático, como el ya mencionado de Atenas con la inscripción de Temístocles (Fig. 6). Ocasionalmente se detecta la presencia de este tipo de epígrafes sobre fondos recortados. En la Península Ibérica hay varios casos, como los de La Cabañeta en El Burgo de Ebro (Mínguez y Díaz Ariño, 2011: fig. 4, n. ${ }^{\circ}$ 11) (Fig. 11A) y, una vez más, los de Mas Castellar de Pontós (Ferrer et al., 2016: figs. 4, 6 y 8) (Fig. 11в). Incluso se han detectado signos no alfabéticos, como sucede en un fondo de sigillata con una espiral encontrado en la plaza del Castillo de Pamplona (Oscáriz y Unzu, 2011: fig. 29).

Este último subgrupo es más difícil de identificar en las publicaciones ya que, con frecuencia, los estudios sobre marcas y grafitti en cerámica aparecen inadecuadamente documentados. La reproducción fotográfica suele centrarse solo en las marcas, dejando de lado el soporte o, en otros 

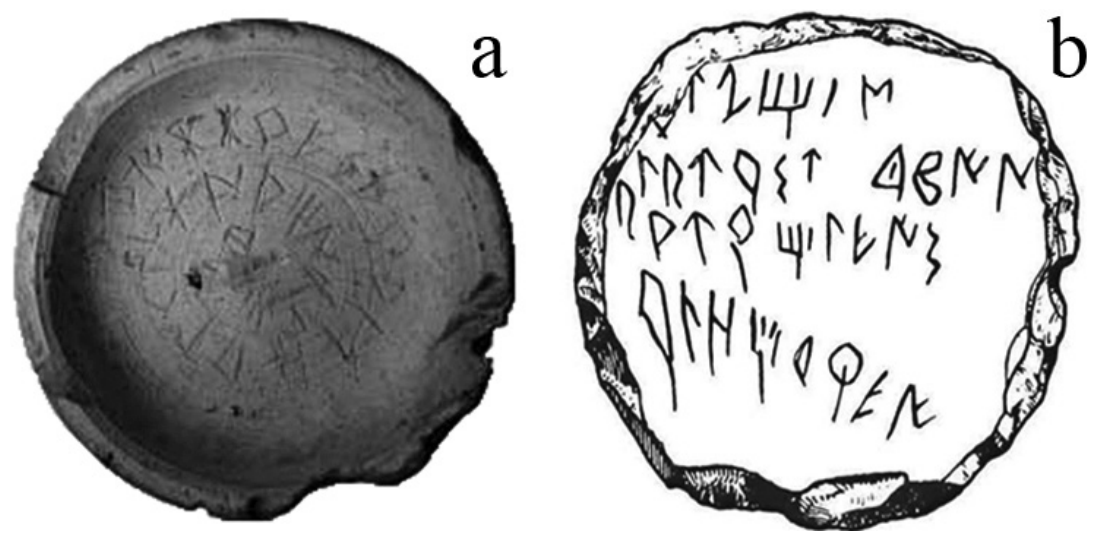

FIG. 11. A) Grafito íbero sobre fondo de cerámica común (Minguez y Diaz Ariño, 2011: 61); B) Ostrakon de Más Castellar de Pontós (Adroher et al., 1993: fig. 19).

del fondo, donde se observan una banda y un filete, $y$, en el centro, un círculo trazado con línea muy fina. En la cara interna del fondo hay una decoración compuesta de diez palmetas radiales ligadas alternativamente, cuyos roleos están muy marcados, y enmarcadas en bandas de estrías decorativas. Está formado por dos fragmentos que dividen la pieza justo por la mitad del vaso. La técnica de recorte se puede seguir con bastante precisión, pues preserva bastante

muchos casos, se opta directamente por no incluir esas imágenes.

En este conjunto de piezas recortadas sobre el pie de una pieza cerámica se adscriben tres piezas del depósito del Zacatín:

— N.o inv. 747 (Fig. 12): pieza recortada sobre el fondo de un plato de pescado de producción púnico-hispánica, respetando el pocito central. No presenta ningún tipo de decoración ni tratamiento especial, aunque podrían estar ocultos bajo las numerosas concreciones que cubren la superficie. La pieza conserva la base en su totalidad. En la parte superior del pozo se puede observar como el borde ha sido tratado y redondeado. Este recorte se ha realizado sobre el pie, ciñéndose completamente al tamaño de este. Medidas: altura, $23 \mathrm{~mm}$; diámetro de borde, $57 \mathrm{~mm}$; diámetro de base, 45 $\mathrm{mm}$; peso, $66 \mathrm{~g}$.

- N. ${ }^{\circ}$ inv. 748 (Fig. 14): pieza recortada sobre fondo de barniz negro ático, una forma abierta tipo fuente, posiblemente Ágora 777-808 o 825-842 -Lamb. 21 o 22-. Se encuentra bastante erosionada y apenas conserva el barniz. Carece de uña y de ombligo en la cara externa bien las puntas que van sobresaliendo, así como la impronta negativa de las lascas que han ido extrayéndose durante el proceso; la fractura dejó una huella concoidea por la presión ejercida sobre la cerámica para hacer saltar las porciones; en algunos puntos encontramos sobre ellas concreciones calcáreas. Vista la naturaleza de estas fracturas estimamos que debieron ser realizadas por presión o percusión indirecta. Existen igualmente una serie de líneas paralelas a la superficie del vaso que han sido producidas por uso, quedando descartadas para ellas el que sean efectos de la manipulación de las mismas en laboratorio ya
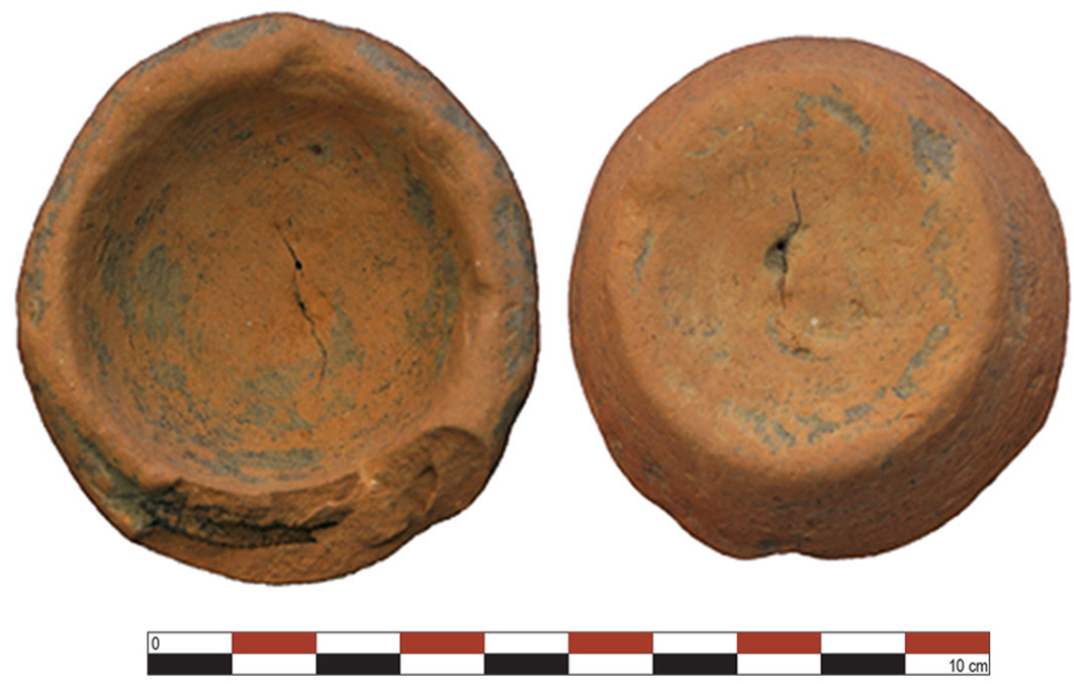

FIG. 12. Anverso y reverso de fondo de plato de pescado púnico (n. ${ }^{\circ}$ inv. 747). 

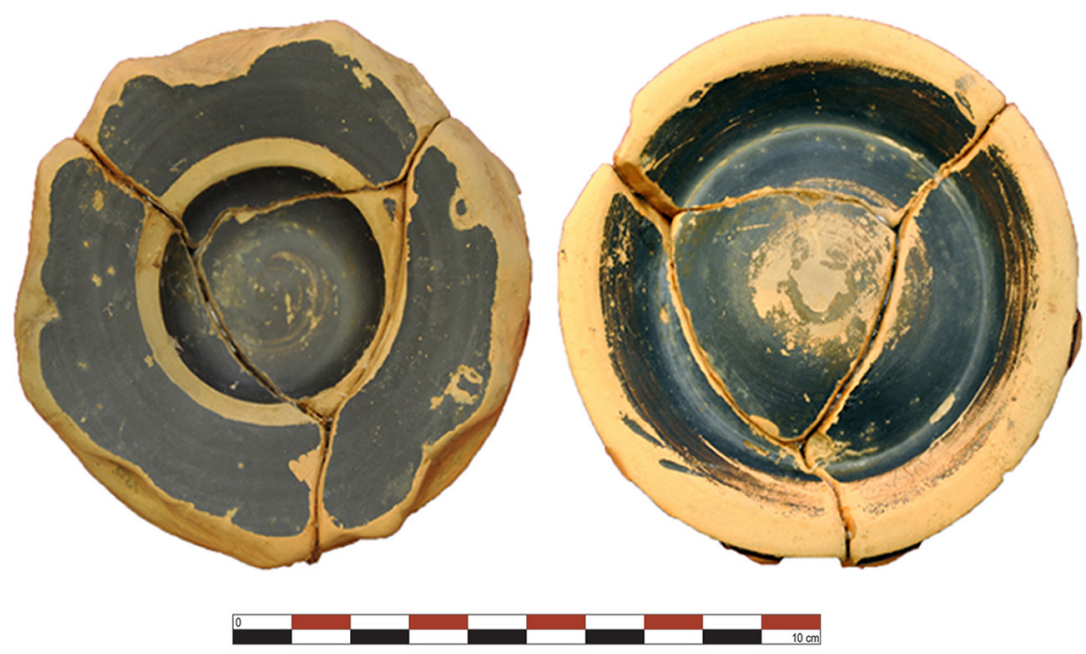

FIG. 13. Anverso y reverso de fondo de plato de pescado griego de barniz negro (n. ${ }^{\circ}$ inv. 749).

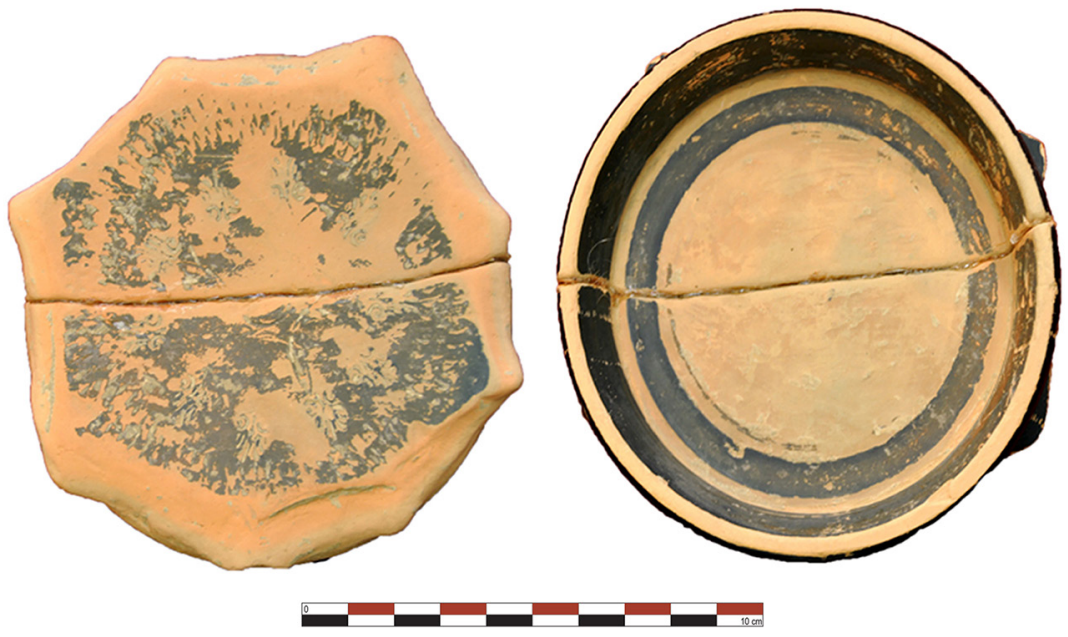

FIG. 14. Anverso y reverso de fondo de plato griego de barniz negro con decoración (n. ${ }^{o}$ inv. 748).

que se sitúan por debajo de las concreciones. Las características de las fracturas nos llevaron a pensar, en un primer momento, en dos opciones a la hora de interpretarlas: que la pieza estuviera realmente finalizada o que estemos ante el caso de una pieza inacabada, de modo que su aspecto actual no sería más que el reflejo de una fase del procedimiento de fabricación. No obstante, dado que la encontramos en un claro contexto funcional, parece más que probable que la pieza esté acabada por completo y este sea el aspecto final de la misma. Dimensiones: altura, $23 \mathrm{~mm}$; diámetro máximo, 113 mm; diámetro de base, $110 \mathrm{~mm}$; peso, $133 \mathrm{~g}$.

- N.o inv. 749 (Fig. 13): pieza fabricada sobre un fondo de cerámica ática de barniz negro, concretamente un plato de pescado -Ágora 1061-1076 o Lamb. 23-. El recorte se ciñe al diámetro del pie. Podría estar tallada siguiendo mismo proceso que en la pieza anterior, observándose una serie de concavidades, quizás como resultado de la extracción de fragmentos por presión, directa o indirecta sobre ocho puntos. Dimensiones: altura, $19 \mathrm{~mm}$; diámetro borde, $85-89 \mathrm{~mm}$; diámetro de pie, $84 \mathrm{~mm}$; peso, $97 \mathrm{~g}$.

Este subgrupo alberga diferentes tipologías y clases cerámicas. Los dos ejemplares en barniz negro no presentan un acabado de las zonas de fractura tan completo como el fondo de plato púnico. Hemos encontrado un paralelo a este tipo de piezas discoidales, como el plato de pescado de Cádiz (Sáez Romero, 2014: 101), pero su contexto no permite justificar nada acerca de su funcionalidad.

Analizando paralelos observamos que, como en los casos anteriores, estas piezas no parecen asociarse a determinados contextos. Fundamentalmente, se encuentran en poblados como el de Ascoy, en Cieza, donde aparecen dos pies recortados sobre cerámica de barniz negro (Lillo, 1981), o en la Cadira del Bisbe, donde hay varios fondos sobre barniz negro perfectamente recortados, a juzgar por la documentación gráfica publicada (Álvarez y Carrasco, 1980: figs. 3, 18, 20 y 21); también en Sant Miquel de Sorba (Cura, 2000: 142). Otras piezas similares las contemplamos con dudas a la hora de incluirlas en este grupo, como 
ocurre como el fondo de copa Cástulo de La Serena (Gracia, 2005: fig. 7).

Un ejemplar interesante en un contexto cerrado de necrópolis es el encontrado en la Tumba 49 de la necrópolis de Puig de Serra, en Ullastret (Martín, 2000: 324), datado por su contexto a mediados del s. IV a. C.; se trata de una pieza discoidal recortada sobre un umbo de cerámica gris de la costa catalana -conocida antiguamente como gris ampuritana-. Podría tratarse de un caso similar a nuestra pieza de la figura 2.03-04, tanto por su perfil, muy similar, o formar parte de un ritual.

Finalmente, hacemos referencia a un caso similar sobre barniz negro (Fig. 5, n.o 24), encontrado en el pecio del Sec (Cerdá, 1987: n. 123).

\subsection{Fondos recortados}

Un tercer grupo que hemos diferenciado entre la cerámica del depósito del Zacatín es el de las piezas discoidales recortadas sobre fondos de kylikes áticos de figuras rojas. En principio, podría asociarse a la categoría precedente, pero el hecho de seleccionar unas clases y formas cerámicas específicas para fabricar las piezas recortadas puede ser reflejo de una intención encaminada a un papel simbólico o, en todo caso, más específico en estas piezas. Además, su realización y terminación, a nivel técnico, parece estar más cuidada.

Se trata de recortar el medallón central de estos kylikes atendiendo a dos cuestiones: en primer lugar, la terminación de la pieza se realiza mediante un pulido más o menos logrado de las zonas de fractura del perímetro de la pieza. En segundo lugar, se detecta la presencia de una pequeña protuberancia que interrumpe claramente la línea del círculo recortado -que responde al fondo decorado-. Esta peculiaridad parece responder a un deseo explícito de dejar un pequeño apéndice que pueda servir como asidero para la sujeción con dos dedos -pulgar e índice-, lo que, a su vez, nos lleva a considerar una funcionalidad concreta para estas piezas.

No ha resultado fácil seleccionar las piezas a incluir en esta categoría. Para ello hemos tenido en cuenta una serie de características: en primer lugar, que en la zona de fractura se puedan observar algunas señales del proceso de recorte, es decir, marcas de presión o su aspecto pulido. Asimismo, hemos considerado que el borde que se genera con el proceso de recorte mantenga una misma trayectoria circular al menos en un 50\%, para así evitar aquellas fracturas que puedan ser fortuitas. Este parámetro de caracterización se estableció a partir del problema que suscitó la pieza n. ${ }^{\circ}$ inv. 752 que, al principio, se incluyó en esta categoría, pero, al revisar con detenimiento los datos conjuntos, pudimos comprobar que, al medir la correspondencia entre una circunferencia y el perímetro de la pieza, solo coincidía en un 34\%; además, aunque parece evidente la existencia de una parte con corte circular, no se aprecia el tratamiento final de las fracturas como en el resto del conjunto.

Por tanto, hay que asumir un rango de desviación en la forma circular que describen los recortes sobre el fondo de los kylikes, que fundamentalmente es consecuencia de las imperfecciones propias del trabajo artesanal. Las fracturas que se producen durante el recorte no siempre pueden ser las buscadas, generándose errores, algunos más o menos soslayados mientras que otros harían desechar la pieza por completo. Esto explicaría que no siempre coincida a la perfección el perfil recortado con los medallones centrales.

Entre las piezas de este tipo documentadas en el depósito del Zacatín encontramos:

- N. ${ }^{o}$ inv. 750 (Fig. 15): tres fragmentos correspondientes a un fondo recortado de kylix de figuras rojas. Presenta el borde pulido con un porcentaje de circularidad del $60 \%$. El medallón central está decorado con una figura masculina vestida con himation; en la cara interna se encuentra una cruceta con tres puntos y debajo un círculo con un punto. Detrás del personaje se encuentra lo que parece una columna salomónica. La cara externa no se conserva muy bien y solo puede verse uno de los registros, donde parece observarse la silueta de dos personajes afrontados: a la izquierda hay una cara femenina y a la 


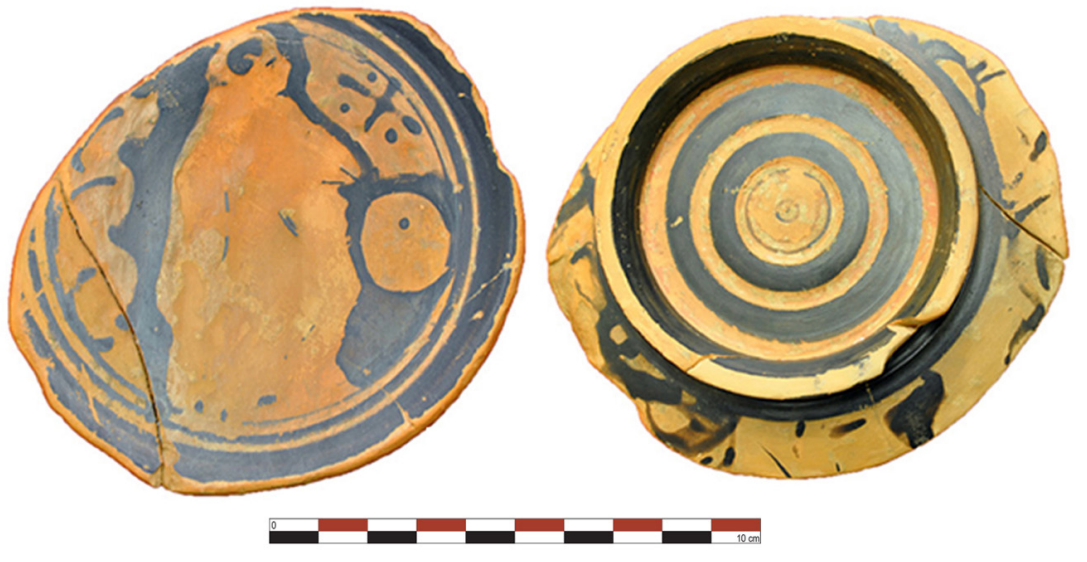

FIG. 15. Fondo de kylix ático de figuras rojas recortado (n. ${ }^{\circ}$ inv. 750).

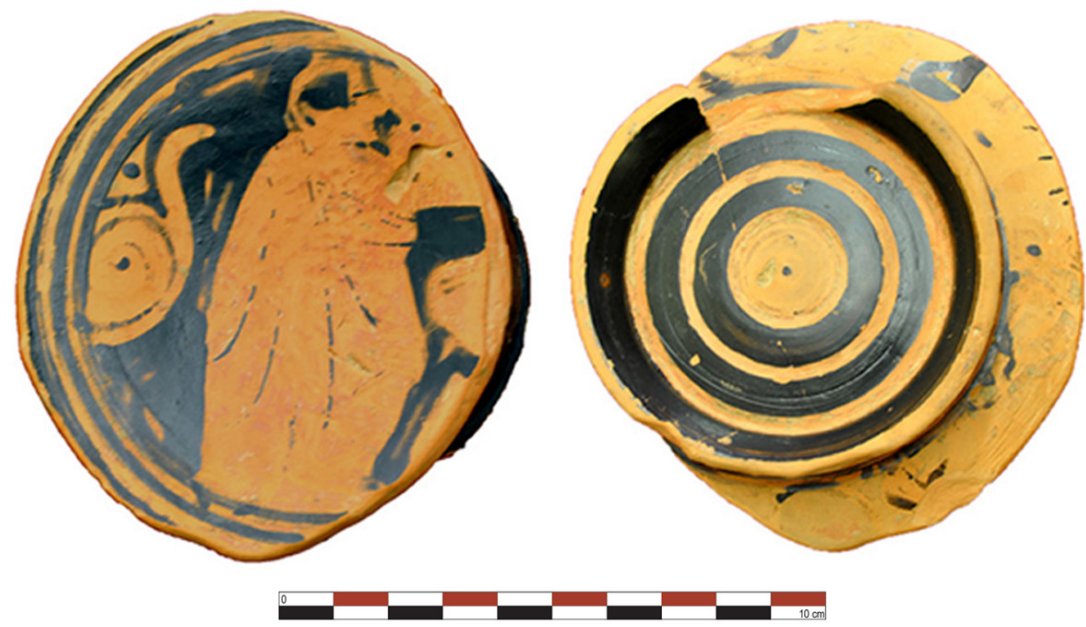

FIG. 16. Fondo de kylix ático de figuras rojas recortado (n. ${ }^{\circ}$ inv. 751 ).

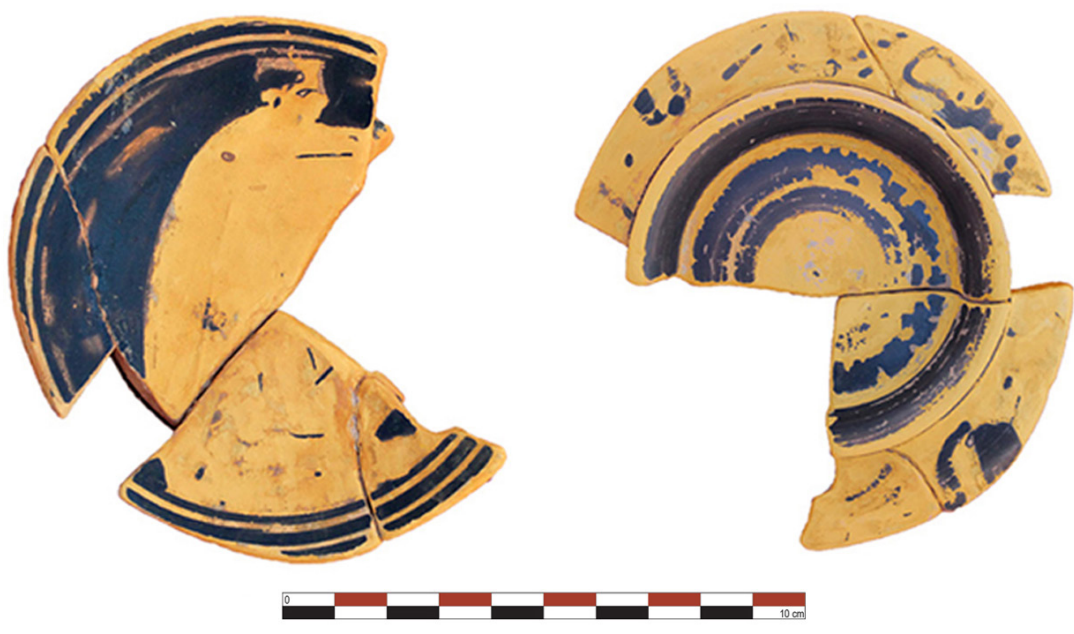

FIG. 17. Fondo de kylix ático de figuras rojas recortado (n. ${ }^{\circ}$ inv. 753). derecha una figura masculina con himation. La cara externa del fondo externo se compone de dos escalones, además presenta doble incisión de puntos linealmente dispuestos que atraviesan gran parte del campo del tondo central de la cara interna. Dimensiones: altura, $16 \mathrm{~mm}$; diámetro de fondo, $75 \mathrm{~mm}$; peso, $85 \mathrm{~g}$. - N.o inv. 751 (Fig. 16): fragmento de un fondo recortado de un kylix de figuras rojas. No se conserva en su totalidad, solamente en un $80 \%$. Esta pieza muestra una característica sobre la que volveremos más tarde y es que en la decoración de la cara interior algunas circunferencias cambian la longitud del radio, confluyendo hacia el centro. Podría decirse que cambia la trayectoria. Mientras que el $50 \%$ del borde tiene un radio amplio y describe un recorrido circular, la mitad derecha parece sufrir una desviación de dicha trayectoria. Todo el reborde ha sido pulido. El tema decorativo en este caso es una figura masculina con himation, a derecha, tras la que se dibuja un roleo; no se conservan indicios para poder describir qué habría delante de la figura. El fondo presenta doble escalón en la cara externa. Dimensiones: altura, $19 \mathrm{~mm}$; diámetro superior, $83-97 \mathrm{~mm}$; peso, $69 \mathrm{~g}$.

- N.o inv. 753 (Fig. 17): pieza discoidal recortada sobre 
fondo de un kylix de figuras rojas. En este caso la pieza está fraccionada en 4 fragmentos. Solo conserva el $64 \%$ del borde recortado, pero la preparación, proyección y pulido están cuidados. La decoración presenta un medallón central donde solo hay una figura masculina a derecha con himation. Carece de resalte en la cara externa del fondo. Dimensiones: altura, $16 \mathrm{~mm}$; diámetro superior, $100 \mathrm{~mm}$; diámetro de base, $69 \mathrm{~mm}$; peso, $49 \mathrm{~g}$.

— N.o inv. 755 (Fig. 18): la pieza ha sido recortada del fondo de un kylix ático de figuras rojas y se presenta partida en cinco fragmentos, aunque se conserva el total del fondo. Tiene un porcentaje de circularidad continua del $76 \%$, si bien la trayectoria del círculo sufre una variación de unos $10 \mathrm{~mm}$. El tratamiento de las fracturas de recorte es algo menos evidente que en las otras piezas, aunque sí se puede apreciar en algunas zonas. En este caso, el tema decorativo también corresponde a una figura masculina a derecha con himation, que aquí aparece frente a un altar con perfil de columna truncada. En la cara exterior no quedan restos de la decoración y el fondo no tiene resalte. Dimensiones: altura, $15 \mathrm{~mm}$; diámetro superior, $91 \mathrm{~mm}$; diámetro de base, $70 \mathrm{~mm}$; peso, $58 \mathrm{~g}$.

- N.o inv. 756 (Fig. 19): pieza discoidal recortada sobre fondo de kylix ático de figuras rojas que, en este caso, se presenta en dos fragmentos. La base se conserva completa. Aunque inicialmente no teníamos claro si incluirla dentro de esta categoría, ya que una parte importante sobresale y no sigue la trayectoria circular del resto del borde recortado, finalmente decidimos adscribirla a este grupo al presentar en la zona del medallón un recorte en circunferencia casi perfecto, apreciándose muy bien el tratamiento de las fracturas. Parece muy escasa la probabilidad de que esto ocurriese de forma aleatoria. La decoración corresponde a un rostro femenino a derecha, con velo-sakkós-, frente a una posible figura arquitectónica -¿columna salomónica?-. En el reverso no se ha identificado ningún motivo y el fondo externo del kylix carece de resalte. Dimensiones: altura, $23 \mathrm{~mm}$; diámetro superior, 103$112 \mathrm{~mm}$; diámetro de base, $72 \mathrm{~mm}$; peso, $92 \mathrm{~g}$.

Una revisión de los temas decorativos de este grupo permite una interesante reflexión ya que la

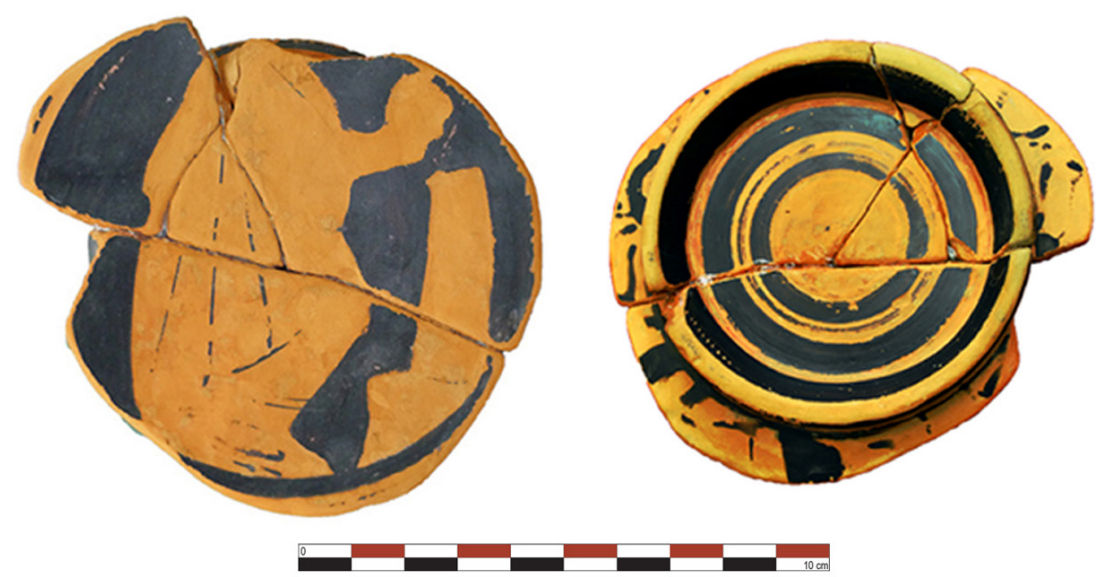

FIG. 18. Fondo de kylix ático de figuras rojas recortado (n. ${ }^{\circ}$ inv. 755).

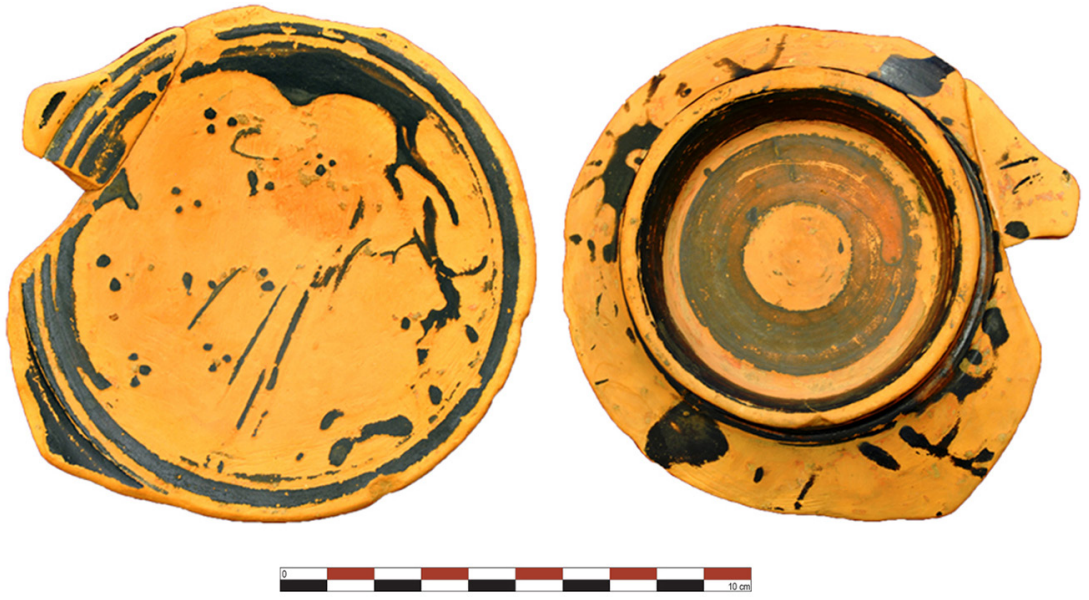

FIG. 19. Fondo de kylix ático de figuras rojas recortado (n. ${ }^{\circ}$ inv. 756). 
variedad temática observada en los kylikes áticos de figuras rojas presentes en el depósito es muy amplia (vs. Rouillard et al., 2017); por ello, sospechamos que se produjo una selección a la hora de recortar en función de sus motivos decorativos. Es el caso de figura masculina a derecha con himation, que aparece en casi todas las piezas de este grupo; solo se añade, como excepción, la pieza con el medallón con cabeza femenina ataviada con sakkós. No hay que olvidar que son cinco ejemplares los que componen este grupo, cifra no muy representativa si tenemos en cuenta que se han cuantificado más de 150 copas áticas de figuras rojas en el depósito (Adroher y Abelleira, 2018: 157); es decir, la muestra que aquí presentamos no alcanza el $4 \%$ dentro de las copas áticas de figuras rojas.

Respecto a la funcionalidad concreta de esta categoría, Olmos (1988-1989) ha planteado la posibilidad de que, tras la rotura accidental de las piezas, algunos fragmentos se recortarían preservándose como un elemento de prestigio y mitificando la imagen central. Es bastante probable que las piezas mantuvieran cierto valor simbólico una vez recortadas, ya que en el conjunto del Zacatín es evidente que se intentado respetar el medallón central. Por otra parte, tras un análisis con lupa óptica no hemos podido detectar ninguna traza de uso en la superficie interna ni en la externa. Consideramos que ambos argumentos podrían invalidar la posibilidad de una funcionalidad directa de la pieza basada solamente en su perfil. Las escasas marcas que se observan han sido producidas por el tratamiento -bien de limpieza o bien de dibujo de las mismas-. Tampoco podemos dejar de lado la posibilidad de que se utilizasen como instrumentos musicales para obtener un sonido por percusión a modo de crótalos, si bien es cierto que esta propuesta carece de apoyo comparativo.

No ha sido fácil rastrear objetos de estas características en las publicaciones. Se conocen algunos casos en ámbito doméstico como en Sant Miquel de Lliria (Olmos y Tortosa, 2009) o en los contextos habitacionales de Mas Castellar de Pontós (Ferrer et al., 2016: fig. 15,1 con grafitti). Un conjunto bien publicado procede del yacimiento galo-etrusco de
Lattara (Chazalon, 2010), donde se hallaron numerosas piezas recortadas sobre fondos de kylikes áticos de figuras rojas, todos ellos procedentes de contextos domésticos ${ }^{4}$.

En ámbito funerario, como en las necrópolis de El Cigarralejo (Cuadrado, 1958 y 1987) o de Coimbra de Barranco Ancho (García Cano y Page del Pozo, 1988; García Cano, 1997), la búsqueda ha resultado infructuosa aunque, dadas las características de estas piezas, es posible que simplemente no se hayan identificado como tales. No obstante, hemos encontrado algunas piezas en la necrópolis de La Albufereta que aparecen recortadas sobre fondos pintados con cabeza femenina (García Cardiel, 2017: 218-219); también hay en la de Baza (Sánchez Fernández, 2017: fig. 3, n. ${ }^{\circ}$ 3), con figura de joven con himation y grafitti púnico en su cara externa, auqnue el sistema de recorte de este fondo es muy diferente al del Zacatín. Sin duda, esos vasos rotos seguían manteniendo un valor para las comunidades que los usaron, posiblemente en relación con la representación figurativa que portaban (Sánchez Fernández, 2017: 188).

Una cuestión a plantear específicamente en relación con el depósito votivo del Zacatín es si las piezas fueron recortadas durante el ritual, es decir, in situ, o ya llegaron recortadas desde el lugar de hábitat. Presentamos algunos argumentos a favor de la segunda opción. El primero es la delicada pulimentación de las zonas de fractura, para lo que se precisaría de tiempo e instrumental que facilitara ese trabajo limpio que delimita tan bien el tondo central; parece poco probable que dicha actividad pudiera practicarse durante el desarrollo de un ritual sagrado.

En este sentido resulta altamente interesante observar el cargamento de El Sec (Trías, 1987), entre cuyas piezas encontramos un numeroso conjunto de piezas recortadas sobre fondos de figuras rojas (Figs. 20-21). Algunas presentan formatos similares a las del Zacatín, como las representadas en las fig. $40,41,47,49,50,57$ y 71 de la publicación original. Especialmente interesante es la de la fig. 45

4 Sin embargo, no están correctamente señalados en la publicación los casos de las figs. 103, 104, 106, 109 y 110. 
(Fig. 20A) porque muestra un tallado muy distinto, similar al que describimos en nuestra categoría anterior ya que no se observa ningún tratamiento sobre la pieza con posterioridad a su fracturación, permaneciendo las marcas discoideas de la presión ejercida para extraer la lasca de cerámica. No se trata de una pieza a medio fabricar, puesto que no respeta realmente el medallón central, sino que lo sobrepasa reduciendo sus dimensiones originales, de modo que la figura del joven ha perdido la cabeza; parece, por tanto, que en este formato lo que mantiene el valor intrínseco no es la iconografía sino el objeto en sí.

Existe otro ejemplo de una pieza recortada con este mismo formato en Cerro Hueco, formando
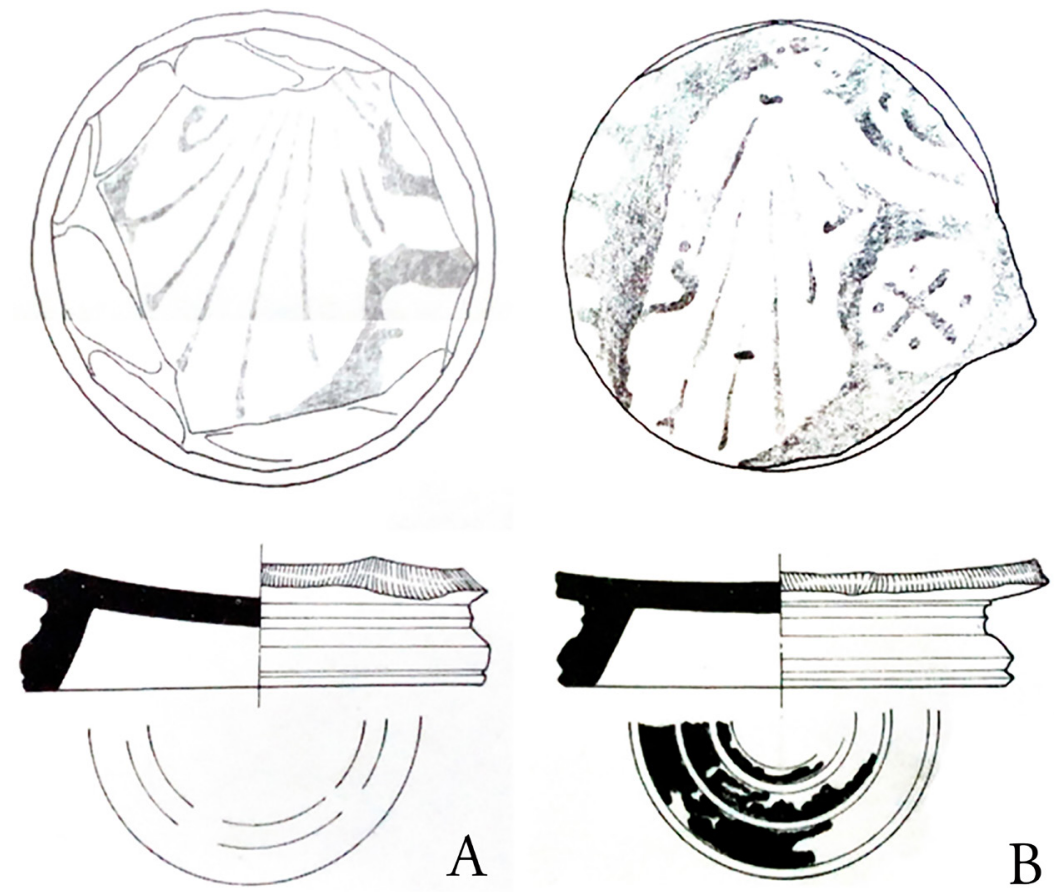

Fig. 20. Fondos de kylikes de figuras rojas procedentes del pecio de El Sec: A) (Trías, 1987: n. ${ }^{\circ}$ inv. 2612, fig. 45, n.o 20); B) (Trías, 1987: n. ${ }^{\circ}$ inv. 2617, fig. 49, n.०21).
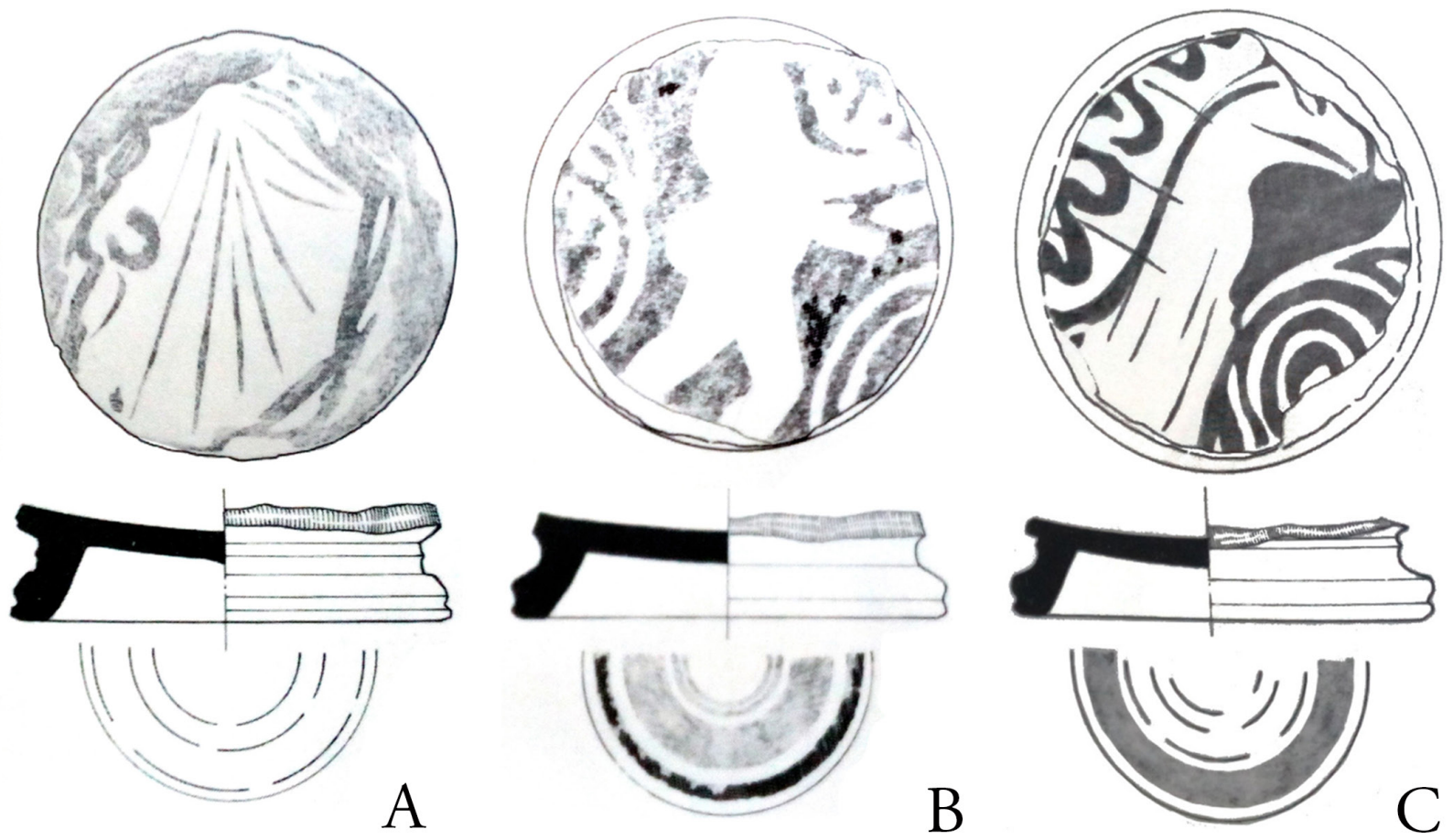

FIG. 21. Fondos de kylikes de figuras rojas procedentes del pecio de El Sec: A) (Trías, 1987: n.o inv. 2611, fig. 50, n. ${ }^{\circ} 22$ ); B) (Trías, 1987: n. ${ }^{\circ}$ inv. 2618, fig. 55, n. $\left.{ }^{\circ} 23\right)$; C) (Trías, 1987: no. inv. 2606, fig. 71, n. ${ }^{\circ} 24$ ). 
parte de un depósito votivo (Machause y Quixal, 2018: fig. 4). Es un fondo de kylix recortado respetando el medallón central que, en este caso, está decorado con una figura animal fantástica de un grifo. Esto permite comprobar que no se trataría de casos aislados, sino de un fenómeno más general que podría confirmarse mediante la correcta publicación de los datos necesarios.

\section{Tipología, morfología y funcionalidad}

Nos encontramos ante un conjunto con una gran complejidad, pues la variedad, tanto de tipologías cerámicas que son talladas, como del tipo específico de recorte y tratamiento que reciben, es muy alta. A su vez, y en esto radica su valor excepcional, el depósito del Zacatín es un raro contexto cronofuncional donde se ha podido documentar tanta diversidad.

En líneas generales, parece más que probable que el valor de estas piezas recortadas no venga definido intrínsecamente por la clase cerámica sobre la que se han elaborado, sino que dependa más bien del uso que hayan adoptado tras su preparación. Es posible que los recortes no eliminen su valor simbólico, sino que lo transformen, especialmente en el caso de los fondos de figuras rojas, la categoría mejor representada en este depósito con una más que evidente vocación sagrada.

Creemos que merece la pena investigar más a fondo este tipo de material, su morfología, técnica de fabricación, contextos, etc., para poder definir sus funcionalidades. Dada la importante representación que encontramos de figuras rojas en ciertos contextos -en el que aquí mostramos del Zacatín pero también en el pecio de El Sec-, sorprende que, en la reciente publicación sobre cerámicas griegas en la Península Ibérica, apenas se refieren tres trabajos que, siempre de pasada, citan piezas recortadas sobre cerámicas (Aquilué et al., 2017).

El caso de El Sec es extraordinariamente interesante puesto que se interpreta como un cargamento de cerámicas griegas dispuesto para su entrada en los mercados peninsulares. La presencia en este pecio de fondos recortados en kylikes de figuras rojas

(C) Universidad de Salamanca hace pensar que estas piezas entrarían en el mercado ya fabricadas y obliga a plantearnos si vendrían directamente preparadas desde los centros productores o si existieron centros redistribuidores -entre los que habría que incluir los propios barcos, al menos potencialmente- que se dedicaran a su preparación. No parece posible aceptar una solución única y consideramos que deberíamos dejar abiertas todas las posibilidades, incluidas las opciones multirrespuesta; es decir, que dependiendo de las circunstancias y necesidades podrían haber sido tanto los centros de producción como los de redistribución, o incluso los propios consumidores finales, quienes realizaran el recorte. La amplísima variedad y tradición de fabricar y usar piezas recortadas parece estar muy enraizada. Finalmente, apuntamos la posibilidad de que esas piezas estuvieran destinadas al uso por la propia tripulación, en cuyo caso no se podría hablar de un comercio de fondos recortados y habría que retomar la propuesta de que son los consumidores últimos quienes realizan todo el proceso de transformación, seguramente aprovechando piezas dañadas con anterioridad.

Puesto que uno de los objetivos de este trabajo es formalizar los estudios sobre estas piezas, consideramos conveniente definir una posible metodología de trabajo mediante modelos descriptivos que ofrezcan una información básica, con la descripción del contexto del hallazgo que posibilite su análisis y permita extraer datos para detectar sus usos. Creemos que, para la elaboración de un análisis adecuado de este tipo de materiales, deberían tenerse en cuenta los siguientes ítems:

a) Soporte: categoría que define la clase cerámica sobre la que se ha practicado el recorte. Esta información parece ser importante en relación a definir su funcionalidad. Casi siempre los recortes se realizan sobre cerámica vascular, aunque también existen otros soportes como el material de construcción -tegulae y latericia-, piedras o incluso vidrio. Es posible que haya correlación entre ciertos materiales y su funcionalidad, como parece suceder con las pequeñas piezas con buena terminación que suelen asociarse a las piezas de juego -barnices negros, sigillata, etc.-.

Zephyrus, LXXXIV, julio-diciembre 2019, 63-88 
b) Morfometría: resulta imprescindible recabar una serie de datos mínimos como el diámetro, grosor y peso de las piezas pues, en líneas generales, parece que estamos ante tres grandes grupos métricos -hay recortes realmente pequeños, inferiores a $5 \mathrm{~cm}$; un grupo intermedio, el más numeroso, entre 5 y $12 \mathrm{~cm}$; y un tercero que supera los $12 \mathrm{~cm}-$. Parece probable que el diámetro sea uno de los parámetros más importantes. Como hemos observado ya, las piezas de juego suelen ser especialmente reducidas, pero las tapaderas, que, lógicamente, deben amoldarse a la apertura de boca del recipiente que deben tapar -ollas, ánforas y cazuelas-, suelen superar los $12 \mathrm{~cm}$ de diámetro, salvo en el caso de botellas y pequeños cuencos. Respecto al grosor, en principio, no hemos detectado que sea una medida definitoria, aunque depende en muchas ocasiones del propio soporte, así como del diámetro máximo, que lógicamente afecta a la anchura media del recorte.

c) Técnicas de recorte: es interesante establecer la cadena operativa -chaîne opératoire- de estas piezas. Para ello, los estudios sobre técnicas de extracción de lascas sobre núcleo y los trabajos en industria lítica tallada en general podrían resultar muy útiles; lo mismo sucede con los del vidrio -ambos suelen tener ciertas concomitancias por la naturaleza de las fracturas que se producen-. Además, habría que observar si las fragmentaciones se han realizado de forma completamente transversal -como en las piezas discoidales- o si son ligeramente tangenciales, como puede observarse en la pieza n. ${ }^{\circ} 45$ de El Sec; esto indica dos modelos diferentes que respetan, o no, la decoración presente en la pieza. También hay casos donde, tras la extracción de las esquirlas, se han regularizado los bordes para evitar zonas apuntadas que pudieran producir cortes. Finalmente, también se debe comprobar si se ha aplicado el tratamiento de alisado o pulido de la zona de fractura (Fig. 24B). El caso más extraño que hasta ahora hemos podido documentar es el de una pieza de Olèrdola, anteriormente referenciada, con un borde dentellado. d) Sector de la pieza de origen tratado: habría que distinguir, en la medida de lo posible, la procedencia original de la pieza recortada -borde, pared, fondo, asa, etc.-. Según los datos que hemos constatado solo se documentan piezas recortadas sobre fragmentos amorfos de pared o sobre fondos, respetando siempre la circularidad de estos. Las paredes resultan más fáciles de recortar y son mucho más versátiles funcionalmente ya que solo las dimensiones del fragmento original determinarían las del producto final. Sin embargo, los fondos son más anchos, de pasta más espesa y su diámetro está determinado directamente por el del pie de la pieza. Son más difíciles de seccionar por la dureza que presenta el mismo pie y que evita una fracturacíon con la misma facilidad que un fragmento de pared. Es obvio que se buscan pies o paredes de cerámica para tallar las piezas discoidales en función del uso posterior que se les va a dar. El uso de los pies con decoración figurativa de la clase fina es un claro ejemplo de búsqueda de una finalidad posterior, quizás simbólica en el caso del Zacatín.

e) Perforaciones y otras alteraciones: a partir de la identificación de transformaciones que vayan más allá de buscar una circularidad en la pieza podemos obtener información ańadida acerca de la funcionalidad. Es frecuente la presencia de una perforación central, sobre cuya funcionalidad hay cierto acuerdo ya que estos discos parecen tener relación con actividades textiles, a modo de fusayolas o de tensores, que son claramente visibles en contextos egipcios (Nelson, 2001; Spinazzi-Luchessi, 2018: 85). Otras alteraciones que podemos encontrar son las mordidas en el borde exterior, como sucede en el caso de Olèrdola, cuya funcionalidad concreta, de momento, es imposible determinar.

f) Grafitti y elementos ańadidos: en ocasiones, los materiales recortados soportan algún tipo de inscripción -ideogramas, letras, acrónimos o textos completos-o símbolos postcocción-zoomorfos, fitomorfos-. En cada caso debería precisarse el lugar exacto donde se encuentra y proporcionar una correcta identificación del mismo. Los casos 
de textos complejos, como el de Pontós, tienen un valor documental diferente a los que presentan una única letra. Además, habría que tener en cuenta que los grafitti como marcas de propiedad son muy frecuentes en la cara externa del fondo de algunas formas abiertas; por ello, es posible que pudieran ser anteriores a la fabricación de la pieza recortada y carecerían de valor para definir la funcionalidad de la pieza discoidal.

g) Decoraciones originales: es interesante, como hemos comprobado en el caso del Zacatín, pero también en otros (Fig. 24C), tener en cuenta si en la pieza se ha respetado o no la decoración original; es decir, comprobar en qué medida permanece completa y si está centrada en el recorte. Para los fondos recortados de cerámicas de figuras rojas quizás este dato sea uno de los que más información ofrecerá a la larga; en los recortes sobre paredes hemos visto que existen algunos casos donde ciertas decoraciones se han respetado, incluso amoldando la forma o dimensiones de la pieza al elemento decorativo representado. No cabe duda de que, para quien fabricase la pieza, esa ornamentación tenía valor añadido.
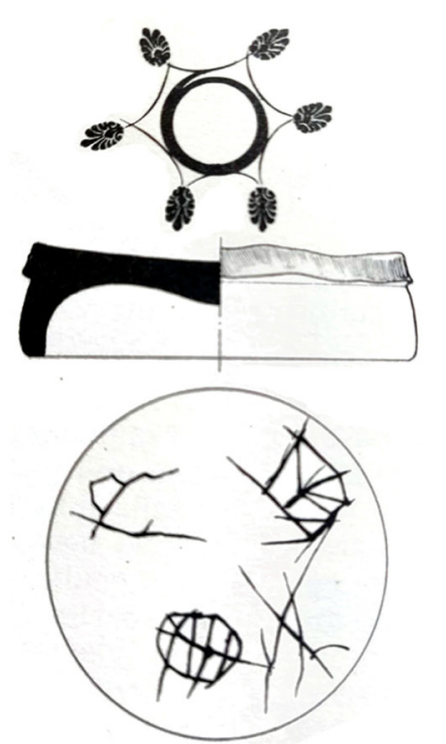

A
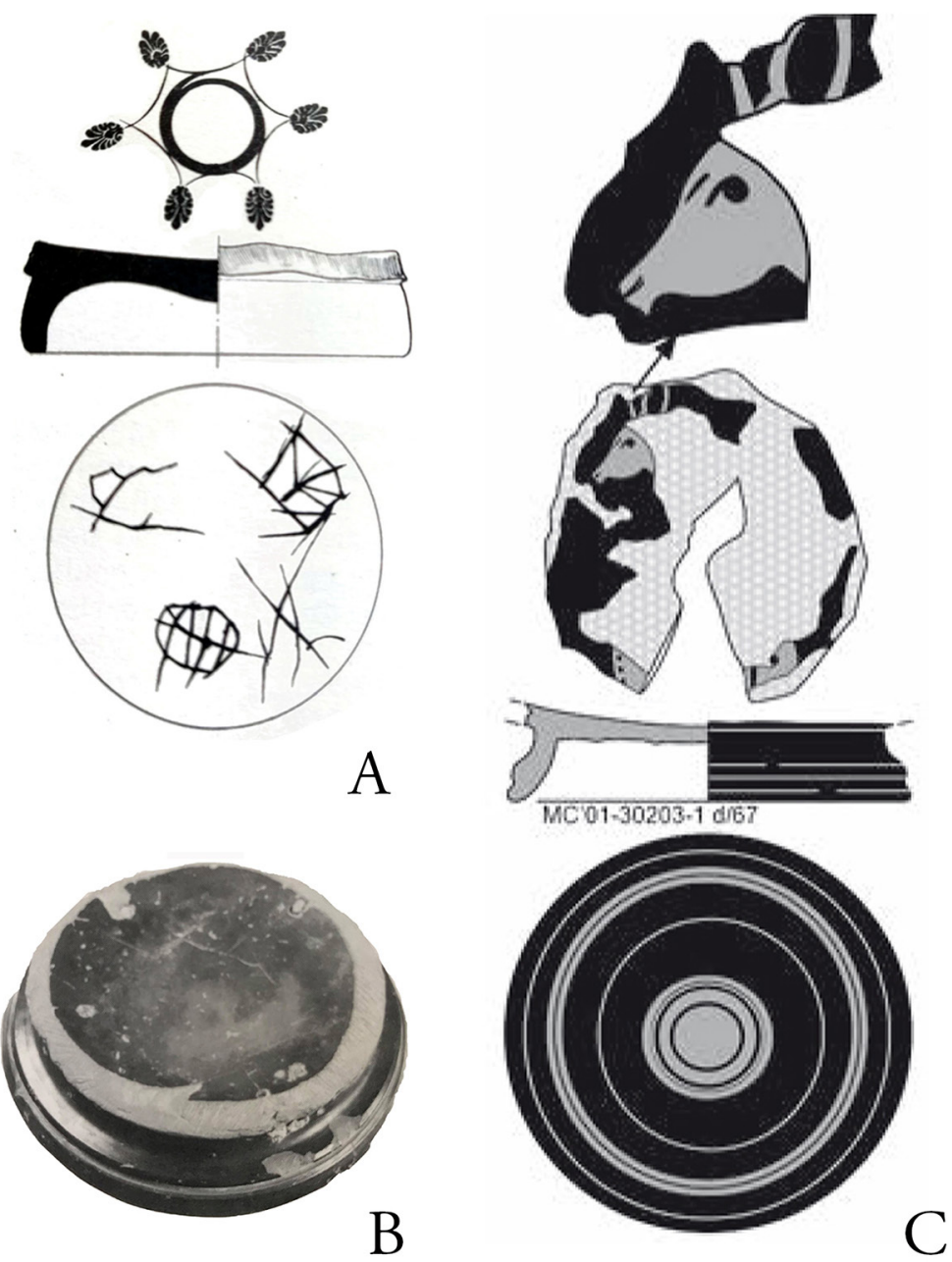

FIG. 22. A) Fondo de pátera de barniz negro ático procedente del pecio de El Sec (Cerdá, 1987: n. ${ }^{\circ} \mathrm{inv}$. 2507, fig. 127); B) pieza con fuerte pulido en la zona de fractura (Knigge, 2005: lám. 107); C) fondo de kylix ático de figuras rojas recortado (Ferrer et al., 2016: fig. 15, n. ${ }^{\circ} 1$ ).

rebordes bien recortados y sin ángulos. Son muy funcionales los fondos de cerámica común al ser

Tras todo lo expuesto, entendemos que las piezas discoidales pudieron haber asumido funciones como:

— Fichas de juego: recortadas sobre cerámicas finas -barnices negros, pintadas, sigillata-, de reducidas dimensiones -diámetro inferior a $5 \mathrm{~cm}-\mathrm{y}$ rebordes pulidos.

- Tapaderas: sobre cerámicas comunes o sobre latericia, con dimensiones superiores a $5 \mathrm{~cm}-\mathrm{el}$ diámetro mínimo de la boca de una botella-, anchos y servir su pie como asidero.

- Pesas de telar: con formato y dimensiones -grosor y diámetro- variados, aunque raramente se tallan sobre cerámicas finas. Presentan una perforación y suelen tener los bordes bien recortados, aunque no pulidos.

- Sistemas de conteo: en cualquier formato, pero con rebordes alisados o, al menos, con los ángulos eliminados. Si aparecen en el mismo contexto tienden a presentar morfometría muy similar. 
- Material simbólico: sobre fondos de piezas de cerámicas finas, preferiblemente con decoración -áticas de figuras rojas-, con rebordes pulidos y de dimensiones determinadas por los diámetros de los fondos de las piezas originales. Es interesante el caso bajo los niveles de habitación del Departamento 1 del Puntal dels Llops (Bonet y Mata, 2002: 148), quizás en relación con un ritual de fundación de la misma.

- Material higiénico: con cualquier formato, aunque entendemos que, por motivos obvios, los rebordes han sido eliminados cuando no directamente pulidos.

- Pesas usadas en las redes de pesca: piezas que presentan perforaciones, al igual que las utilizadas como pesas de telar. El orificio es necesario para engarzarlas dentro de la red de pesca (Bernal, 2008: 186).

- Otros usos en la mesa: como piezas de servicio, pero funcionalidad distinta a la original. Por ejemplo, una copa que, al recortarse, pierde su capacidad como contenedor de líquidos, pero puede considerarse como un plato con la función de servir alimentos sólidos.

\section{Conclusiones}

En el caso del depósito de la calle Zacatín no deja dudas de que, si efectivamente todas las piezas corresponden al depósito, puede asignárseles una funcionalidad bien diferenciada en cada caso. Así, las piezas recortadas como fichas (Figs. 7 y 8) corresponden a elementos de cuantificación, posiblemente ajenos a la esencia sagrada del depósito. Los fondos de plato de pescado (Figs. 12 y 13) podrían haber sido neocontenedores, relacionados con alguna parte del ritual, y, para terminar, tanto los fondos de kylikes como el fondo de barniz negro decorado (Fig. 14) debieron tener un valor simbólico diferente para unos y otros, dependiendo de la iconografía, cuya comprensión se nos escapa de momento. Podemos igualmente resaltar que los recortes, en general, no parecen afectar a tipos cerámicos concretos, salvo en el caso de los kylikes, lo que resaltaría su carácter ritual.

Reconocemos que todas estas consideraciones no son más que apuntes para resaltar la necesidad de identificar, clasificar, describir y publicar adecuadamente este material que responde a modelos de comportamiento difícilmente interpretables de momento, sobre todo, por la escasez de piezas correctamente publicadas.

Muy interesante desde el punto de vista interpretativo es el cargamento localizado en El Sec. Como ya comentamos antes, existe un numeroso conjunto de piezas claramente recortadas, especialmente sobre fondos de kylikes áticos de figuras rojas, pero también sobre un fondo de una posible pátera de barniz negro. Si efectivamente estas piezas pertenecen propiamente al cargamento habría que plantear el motivo por el que se incluyeron en el mismo y, por tanto, habría que considerar si vinieron ya recortadas de su lugar de origen, algo que nos parece poco probable. La otra opción es considerar que formasen parte del material en uso por la tripulación. En ese caso podemos asumir que los marineros usaran esas piezas con alguna función ritual, para juegos o con fin musical. Esto relajaría ciertamente la presión que solemos ejercer sobre ciertas piezas sobre las cuales proyectamos interpretaciones rituales, especialmente cuando su función nos resulta del todo desconocida.

Para concluir hay que tener en cuenta la dificultad a la hora de encontrar materiales correctamente reflejados en las publicaciones y, sobre todo, adecuadamente contextualizados. Por tanto, planeamos este trabajo más como una llamada de atención y un apoyo a los próximos estudios que se realicen sobre este tipo de material, sabiendo que no hemos llegado a clarificar totalmente el panorama en relación a este tema, pero entendiendo que nuestra propuesta puede ser el punto de partida para nuevos trabajos en los que las piezas discoidales recortadas obtengan la atención que merecen y, de esa forma, tengamos, progresivamente, información de sus usos. 


\section{Bibliografía}

Adroher, A. M. (2016): "Arqueología en torno al territorio romano de Abla (Almería)". En Ortiz Ocaña, A. J. (coord.): El mundo romano de Alba (Abla-Almería). Administración, sociedad y economía. Almería: Diput. Provincial, pp. 39-78.

Adroher, A. M. y Abelleira, M. (2018): “Testeo sobre sistemas de cuantificación en ceramología antigua. La aplicación de los Protocolos de Sevilla sobre un contexto votivo ibérico de Iliberri (Albaicín, Granada)". En Remesal, J.; Revilla, V. y Bermúdez, J. M. (eds.): Cuantificar las economías antiguas. Problemas $y$ métodos. Col.lecció Instrumenta, 60. Barcelona, pp. 137-160.

Adroher, A. M.; Carreño, J. C.; Coria, J. C.; González, J. A.; Marañón, R.; Martín, J.; Moreno, C.; Moreno, D.; Ortiz, B.; Ramírez, S. y Roldán, A. (2018): "El Pamplinar (Rute, Córdoba)", Cuadernos Técnicos de Patrimonio, 7, pp. 100-103.

Adroher, A. M.; Pons, E. y Ruiz de Arbulo, J. (1993): "El yacimiento de Mas Castellar de Pontós y el comercio del cereal ibérico en la zona de Emporion y Rhode (ss. IV-II a. C.)", Archivo Español de Arqueologia, 66, pp. 31-70.

Adroher, A. M.; Sánchez, A. y De la Torre, I. (2015): "Cuantificación en cerámica, ¿ejercicio especulativo o ejercicio hipotético? Las cerámicas ibéricas y púnicas en la Iliberri del siglo IV a. C. procedentes del depósito de la calle Zacatín (Granada)", Archivo Español de Arqueología, 88, pp. 39-65.

Agustí, B.; Martín, A. y Pons, E. (2008): "Dipòsits infantils als poblats ibers empordanesos (Catalunya)". En Gusi, F.; Murial, S. y Olària, C. (eds.): Nasciturus, infans, puerulus. Vobis mater terra. $\mathrm{La}$ muerte en la infancia. Castellón: Diput. Provincial, pp. 117-142.

Álvarez, J. y Carrasco, A. (1980): “Un lote de cerámica ática y campaniense del poblado ibérico de la $\mathrm{Ca}$ dira de Bisbe (Premià de Dalt, Maresme)", Pyrenae, 15-16, pp. 241-250.

Aquilué, X.; Cabrera, P. y Orfila, M. (eds.) (2017): Homenaje a G. Trías Rubiès. Cerámicas griegas de la Peninsula Ibérica: cincuenta años después (19672017). Barcelona: Iberia Graeca.

Bernal, D. (2008): "Arqueología de las redes de pesca. Un tema crucial de la economía marítima hispanorromana", Mainake, 30, pp. 181-215.

Bonet, H. y Mata, C. (2002): El Puntal dels Llops. Un fortín edetano. Trabajos Varios del sip, 99. Valencia.
Broncano, S. (1989): El depósito votivo ibérico de El Amarejo. Bonete (Albacete). Excavaciones Arqueológicas en España, 156. Madrid: Ministerio de Cultura.

Castro, Z. (1978): "Piezas discoidales en yacimientos del Nordeste de Cataluña", Cypsela, 2, pp. 173-196.

Cerdá, D. (1987): "La cerámica ática de barniz negro". En Arribas, A.; Trías, G.; Cerdá, D. y De Hoz, J. (eds.): El barco de El Sec (Costa de Calvià, Mallorca). Estudio de los materiales. Mallorca: Univ. Illes Balears, pp. 197-399.

Charlier, P.; Brun, L.; Pêtre, C. y Huynh-Carglier, I. (2012): "Toilet hygiene in the classical era", British Medical Journal, 345, p. e8287.

Chazalon, L. (2010): "Les céramiques attiques du ve s. av. n. è. à Lattes”, Lattara, 21, pp. 529-650.

Cuadrado, E. (1958): "Cerámicas griegas de figuras rojas en la necrópolis de El Cigarralejo", Archivo Espanol de Arqueología, 31, pp. 98-125.

Cuadrado, E. (1987): La necrópolis ibérica de El Cigarralejo (Mula, Murcia). Bibliotheca Praehistorica Hispana, 23. Madrid: Csic.

Cura, M. (2000): "Les ceràmiques gregues i de vernís negre del jaciment de Sant Miquel de Sorba (Montmajor, Barcelona)", Quaderns de Prehistoria i Arqueología Castellonencs, 21, pp. 137-152.

De Hoz, J. J. (2011): “Lengua y escritura”. En Bonet, H. y Vives-Ferrándiz, J. (coords.): La Bastida de les Alcusses, 1928-2010. Valencia, pp. 221-237.

Ferrer, J.; Asensio, D. y Pons, E. (2016): "Novetats epigràfiques ibèriques dels segles V-IV a.C. del Mas Castellar (Pontós, Alt Empordà)", Cypsela, 20, pp. 117-139.

Fletcher, D.; Pla, E. y Alcácer, J. (1969): La Bastida de les Alcuses (Mogente, Valencia), II. Trabajos Varios del sip, 25. Valencia.

García Cano, J. M. (1997): Las necrópolis ibéricas de Coimbra del Barranco Ancho (Jumilla, Murcia). I. Las excavaciones y estudio analitico de los materiales. Murcia: Univ. de Murcia.

García Cano, J. M. y Page, V. (1988): "La cerámica de figuras rojas de la necrópolis de 'La Senda' Coimbra del Barranco Ancho (Jumilla)", Anales de Prehistoria y Arqueología de la Univ. de Murcia, 4, pp. 125-135.

García Cardiel, J. (2017): "Vasos griegos en la necrópolis de la Albufereta (Alicante): signos helenos para discursos contestanos". En Aquilué, X.; Cabrera, P. y Orfila, M. (eds.): Homenaje a Glòria Trías Rubiès. Cerámicas griegas de la Península Ibérica: cincuenta años después (1967-2017). Barcelona: Iberia Graeca, pp. 213-220. 
Gracia, F. (2005): "Las cerámicas griegas en el área occidental de la Península Ibérica entre los siglos vi y IV a.C. El conjunto de materiales del palacio-santuario de Cancho Roano (Zalamea de la Serena, Badajoz)". En Celestino, S. y Jiménez, J. (eds.): El periodo orientalizante. Anejos de Archivo Español de Arqueología, 35. Mérida: csic, pp. 1173-1197.

Herrera, M. D. y Gómez, F. (2004): Tell Abu Hawam (Haifa, Israel). El horizonte fenicio del Stratum III británico. Salamanca-Huelva: Univ. de Huelva.

Knigge, U. (2005): Der Bau Z, Kerameikos. Ergebnisse der Ausgrabungen. Band xvII. München: Hirmer.

Lillo, P. (1981): El poblamiento ibérico en Murcia. Murcia: Univ. de Murcia.

Machause, S. y Quixal, D. (2018): "Cuevas rituales en el territorio de Kelin (ss. v-III a. C.)”, Complutum, 29, pp. 115-134.

Martín, A. (2000): "Tumba 49 de la necrópolis ibérica del Puig de Serra, Serra de Daró (Ullastret)". En CAbrera, P. y Sánchez, C. (eds.): Los griegos en España. Tras las huellas de Heracles. Madrid: Ministerio de Cultura, pp. 316-324.

Mínguez, J. A. y Díaz Ariño, B. (2011): "Grafitos sobre cerámica -ibéricos, latinos griegos y signos- procedentes del yacimiento romanorrepublicano de La Cabañeta (El Burgo de Ebro, Zaragoza)", Archivo Español de Arqueología, 84, pp. 51-86.

Molist, N. (2009): "Peces discoïdals". En Molist, N. (ed.): La intervenció al sector 01 del Conjunt Històric d'Olèrdola. De la Prehistoria a l'etapa romana (campanyes 1995-2006). Monografies d'Olèrdola, 2. Salamanca, pp. 401-403.

Morena, J. A. (1991): "El yacimiento protohistórico de El Castellar (Cañete de las Torres, Córdoba)", Anales de Arqueología Cordobesa, 2, pp. 99-166.

Nelson, K. (2001): "The pottery of Nabta Playa: a summary". En Wendorf, F. y Schild, N. (eds.): Holocene settlement of the Egyptian Sahara. Boston, vol. 1, pp. 534-543. http://dx.doi.org/10.10007/978-14615-0653-9_20

Oliver, A. y Gusi, F. (1995): El Puig de la Nau. Un hábitat fortificado ibérico en el ámbito mediterráneo peninsular. Monografies de Prehistória i Arqueología Castellonenses, 4. Castelló.

Olmos, R. (1988-89): "Originalidad y estímulos mediterráneos en la cerámica ibérica: el ejemplo de Elche”, Lucentum, 7-8, pp. 85-86.

Olmos, R. y Tortosa, T. (2009): "Vasos griegos en Iberia: diversidad de espacios y usos sacros". En Funelli, S. y Masseria, C. (coords.): Ceramica attica da santuari della Grecia, della Ionia e dell'Italia. Atti Convegno Internazionale (Perugia, 2007). Osanna, pp. 57-70.

OsCÁriz, P. y Unzu, M. (2011): "Grafitos figurativos, palmas, tridentes y otros signos en cerámica romana de la plaza del castillo de Pamplona", Príncipe de Viana, 253, pp. 79-95.

Panosa, M. I. (1998): "Recull d'epígrafs ibèrics al Vallés Oriental. Aportació al significat de l'estructura indígena en el procés de romanització", Anexos de Ítaca, I, pp. 461-476.

Panosa, M. I. (2001): "Novedades de epigrafía ibérica en Cataluña y algunos aspectos metodológicos". En Villar, F. y Fernández, M. a P. (eds.): Religión, lengua y cultura prerromanas de Hispania. Salamanca: Univ. de Salamanca, pp. 511-540.

Panosa, M. I. (2002): "Epigrafia ibèrica a Mas Castellar de Pontós". En Pons, E. (dir.): Mas Castellar de Pontós (Alt Empordà). Un complex arqueològic d'època ibérica (Excavacions 1990-1998). Sèrie Arqueòlogica, 21. Girona, pp. 577-574.

Papadopoulos, J. K. (2002): “A contextual approach to pessoi (gaming pieces, counters or convenient wipes?)", Hesperia, 71, pp. 423-427.

Peche-Quilichini, K.; Rageot, M. y Regert, M. (2017): "Systèmes de reparation, de réutilisation et de recyclage des vaiselles céramiques protohistoriques en Corse", Bulletin de la Société Préhistorique Française, 114, pp. 137-166.

Pérez González, C. y Arribas, P. (2016): “Cerámicas con grafito y algunos sigilla en TsH de Termes", Oppidum, 12, pp. 85-147.

Potter, T. y Brown, I. W. (2011): "The ceramic discoidal in the Southeastern United States", The University of Alabama McNair Journal, 11, pp. 89-109.

Rambla, J. A. y Salado, J. B. (2002): "Hallazgos de época ibérica y musulmana junto a la alcaicería de Granada”. En Anuario Arqueológico de Andalucía, 1999/ III. Sevilla: pp. 175-185.

Rizkana, I. y Seener, J. (1989): The non-lithic small finds and structural remains of the predynastic settlement. Mainz am Rheim.

Rodríguez NovoA, A. A. (2014): "Elementos cerámicos de la actividad textil en el conjunto arqueológico de Armea (Allariz, Ourense)". En MoraIs, R.; FerNÁNDEZ Fernández, A. y Sousa, J. M. (coord.): As produçôes cerámicas de imitação na Hispania. Monografias Ex Hispania Romana, II. Porto, pp. 397-406.

Rouillard, P.; De la Torre, I. y SÁnchez, A. (2017): "Las cerámicas griegas de figuras rojas de Zacatín 
(Granada, España)", Archivo Español de Arqueología, 90, pp. 271-298. http://dx.doi.org/10.3989/aespa.090.017.012

Sáez Romero, A. M. (2014): "Oculto bajo el barniz. Aproximación inicial a las producciones grises de $G a$ dir de época tardoclásica-helenística (siglos -IV/-III)". En García Fernández, F. J. y García Vargas, E. (eds.): Comer a la moda. Imitaciones de vajilla de mesa en Turdetania y la Bética occidental durante la Antigüedad (ss. VI a.C. - VI d.C.). Col.lecció instrumenta, 46. Barcelona, pp. 79-118.

Sánchez Fernández, C. (2017): "Contexts of use of fourth century Attic pottery in the Iberian Peninsula”. En Rodríguez PÉrez, D. (ed.): Greek art in context: archaeological and art historical perspectives. London-New York, pp. 185-197.

Sánchez Moreno, A.; Niveau de Villedary, A. M. y Adroher, A. M. (2015): "¿Solamente platos?
Cerámicas de barniz rojo en el depósito ibérico del Zacatín (Granada)", Saguntum, 47, pp. 51-72.

Silverman, H. (1993): Cahuachi in the ancient Nasca World. Iowa: Univ. of Iowa Press.

Sol, J.; Adroher, A. M.; García González, J. y De la Torre, I. (2018): "Objetos de vidrio en un conjunto cerrado en Iliberri (Granada) en el siglo IV a. C.”, Pyrenae, 49, pp. 37-60. http://dx.doi.org/10.1344/ Pyrenae2018.vol49num2.2

Spinazzi-Luchessi, C. (2018): The Unwound Yarn. Birth and development of textile tools between Levant and Egypt. Antichistica, 18. Venice: Edizioni Ca'Foscari.

Trías, G. (1987): "La cerámica ática de figuras rojas". En Arribas, A.; Trías, G.; Cerdá, D. y De Hoz, J. (eds.): El barco de El Sec (Costa de Calvià, Mallorca). Estudio de los materiales. Mallorca: Univ. Illes Balears, pp. 47-196. 